\title{
Response of Slope Made Up of Soil and Other Waste Materials under Sinusoidal Motion
}

\author{
Nipa Chanda, Sima Ghosh, and Manish Pal \\ NIT Agartala, Agartala, India \\ Correspondence should be addressed to Nipa Chanda; nipachanda@gmail.com
}

Received 11 April 2017; Revised 22 June 2017; Accepted 11 July 2017; Published 14 August 2017

Academic Editor: Hossein Moayedi

Copyright (C) 2017 Nipa Chanda et al. This is an open access article distributed under the Creative Commons Attribution License, which permits unrestricted use, distribution, and reproduction in any medium, provided the original work is properly cited.

Performance of small scale embankment slopes under dynamic loading is experimentally evaluated in the present work conducting shake table test. Model slopes are made up of soil and soil dust mixtures at various water level conditions. Material dust types as taken in the experiment are saw dust, stone dust, brick dust, and building demolish dust. Shear strength of soil such as cohesion and internal friction angle increases on an average $25 \%$ and $23 \%$, respectively, when soil is mixed with $30 \%$ building demolish dust at different water content. Similarly other dust materials also enhance shear strength of soil. Responses of model slope on the basis of laboratory test have been observed and presented. At base frequency $5 \mathrm{~Hz}$ and $6 \%$ water content condition RMSA decreases up to $57 \%$ when slope material is changed from soil to "S $+30 \% \mathrm{DD}$ " for slope with inclination $45^{\circ}$ and at the same condition slope shows better stability which is reflected from reduction of base displacement as well as crest deformation up to $89 \%$ and $58 \%$, respectively. Analytical solution of slope considering planer rupture surface is done using pseudodynamic method and results are compared with experimental observation. It is seen that when soil is mixed with $30 \%$ stone dust, sliding displacement of slope with inclination $45 \circ$ is $7.5 \mathrm{~mm}$ at shake table test which is very closer to the analytical result. Stability of slope is maximum when "soil and building demolish dust" mixture is used and gradually reduces when slope material changes from "soil and brick dust," "soil and stone dust," "soil and saw dust" mixture, and ultimately soil. Thus, different material dust which we treat as waste can be used at various field conditions to enhance stability of embankment slope.

\section{Introduction}

Safety evaluation of slope against devastation under seismic loading condition is one of the most trending research areas in the field of geotechnical engineering as well as in transportation engineering. Study on slope stability and monitoring of slope movement is done many a time by researchers (Taylor [1, 2], Fellenius [3], and Newmark [4]). Slope shows a stable behaviour under static condition which can simply collapse under seismic loading condition due to the development of seismic inertia forces which acts along with weight of the potential soil mass leading decrease in the strength parameters of soil. The vulnerability of earth structure to ground motion is clearly understood after devastation caused due to different earthquakes recorded during past years. Slope in the form of embankment or cutting many times undergoes severe distress (example Bhuj earthquake in India [5]) and performance of these embankments during earthquake can be analysed by doing instrumentation and monitoring these actual embankments. However, due to different barrier in reality model tests in the laboratory are the only way to study the seismic behaviour of these embankments. To understand the behaviour of embankment slope under dynamic condition model test can be conducted on shake table. Clough and Pirtz [6] are the first to study the performance of slope using shake table. Furthermore, Seed and Clough [7], Goodman and Seed [8], and Arango and Seed [9] used staking table test and observed response of embankments and dams. Response of soil, pile, and fluid interaction during earthquake was studied by Iai [10] by using shake table. A series of shake table tests were done by Koga and Matsuo [11] to see the response of earthen embankment founded on saturated sand under earthquake loading and they observed that slumps and cracks were formed due to softening of underlying ground. Recently Wartman et al. [12-14] conducted small scale shake table 
tests to study slope deformations during seismic condition and to assess the applicability of Newmark's sliding block method of analysis and observed largest deformation due to shaking being near the toe of slopes. A $0.5 \mathrm{~m}$ high $30^{\circ}$ inclined sandy slope was analysed by Lin and Wang [15] and they observed that responses of slope became nonlinear after $0.5 \mathrm{~g}$ loading. Prasad et al. [16] used laminar shear box to enhance the accuracy in assessing ground behaviour and reported calibration and testing of slopes.

Apart from all the experimental works theoretical analysis of slope was done by many researchers to obtain safety factor of slope (Ling et al. [17], Ling et al. [18]) using pseudostatic method where inertia forces were calculated as product of seismic coefficients recommended by researchers (Terzaghi [19]) and weight of the failure wedge does not depend on time and is unable to show the dynamic nature of earthquake loading. The limitation of pseudo-static method was sorted out by Steedman and Zeng [20] and pseudodynamic method is introduced which is able to show the influence of the phase and amplitude variations of earthquake acceleration with depth, velocity of seismic waves, and the period of lateral shaking. Factor of safety of homogeneous slope has been analysed by Chanda et al. [21] using the pseudodynamic method and shows effects of seismic forces and soil strength parameters on the factor of safety of slope.

All these studies give very positive indication to conduct more research to observe response of embankment slopes under seismic condition. Therefore in the present work a series of shake table tests is conducted to study the response of model slope made up of soil and soil with other waste materials under dynamic loading. Four types of waste materials such as saw dust, stone dust, brick dust, and building demolish dust are mixed with soil to enhance the strength parameters, that is, cohesion and angle of internal friction of soil, and model slopes made up of these mixtures are tested under dynamic loading using shake table. Responses of model slopes are presented in terms of RMSA along slope height, displacement at base of slope, and crest deformation of model slopes under dynamic loading at different water content. As the pattern of failure surface in shake table test result is found to be almost linear, an analytical solution of slope using pseudodynamic method has been carried out considering planer rupture surface. Results obtained from shake table test on model slope in terms of sliding displacement are compared with evaluated sliding displacement from analytical solution.

\section{Test Set-Up and Method of Experiment}

2.1. Shaking Table. The uniaxial shaking table experimental set-up in the laboratory consists of a $1.0 \mathrm{~m} \times 1.0 \mathrm{~m}$ base plate (table) fitted with smooth wheels at the bottom which allow sliding in a horizontal direction on two parallel rails. A slotted disc made up of mild steel is bolted to another circular disc of the same size. The supported disc is connected to the shaft of the motor. A steel crank shaft is connected to the slotted disc by bolts. The end of the crank shaft is connected to a reciprocating rod which has maximum stroke length of $150 \mathrm{~mm}$ and a peak frequency of $50 \mathrm{~Hz}$. The amplitude of the sinusoidal motion can be varied by changing the position of the crank shaft in the calibrated slot of the disc. The other end of the reciprocating rod is connected to the shaking table base plate. The reciprocating shaft with the help of slotted disk is fitted with 7.5 H.P. reciprocating motor which can run with speed near about $1400 \mathrm{rpm}$. The frequency of the input motion is adjusted by using an electrical variant. Figure 1(a) shows the experimental set-up in the laboratory. A $12 \mathrm{~mm}$ thick Perspex box of size $80 \mathrm{~cm} \times 58 \mathrm{~cm} \times 35 \mathrm{~cm}$ $(l \times b \times h)$ is used to conduct test on model slope using that shake table as shown in Figures 1(b) and 1(c) because the deformation of slopes from sides can be easily visible through Perspex glass sheets. The front side of the box is marked with light colour ink so that all deformations after test can be measured manually. Sides of the box were fixed rigidly with steel angles to prevent any movement. It has been observed by Whitman and Lambe [22] that soil located in close proximity to rigid boundary walls responded differently than soil near the middle of the model; besides that, reasonably correct physical model test data can be obtained in rigid wall containers. Analysis of soil structure in most of the cases is done by modeling the structure consisting of rigid boundary condition. Therefore, in the present study a rigid wall box was selected the boundary condition of which matches with analytical model. The three inner sides of the Perspex glass box are glued with $10 \mathrm{~mm}$ thick sponge sheets to minimize the boundary effects such as reflection of waves during shaking. Soil particles were glued to the inner bottom surface of the model box to generate surface roughness to control slippage between the base of the model slope and bottom surface of the container during shaking. Acceleration responses of the base plate, container and the model slopes during shaking were measured using B \& K 4507001 type accelerometers. The Bruel \& Kjaer Pulse 6.1 frontend system was used for the data acquisitions. Performance of the experimental setup before starting test on model slopes was checked by system calibration by assuring amplification produced by the system is negligible.

\subsection{Material for Slope Model. Soil procured from National} Institute of Technology Agartala campus is the main ingredient used to prepare model slopes. The soil is classified as silty sand according to the Indian standard soil classification system. The grain size distribution and mineral composition of soil are presented in Figures 2(a) and 2(b). To enhance the strength of the soil four types of dust are used as shown in Figure 2(c). These dust types are saw dust, stone dust, brick dust, and building demolish dust. The surface structure of different materials used to construct model slope is analysed and SEM images along with variation in elemental composition detected by EDX study are presented in Figure 3. Gradation and basic properties of stone dust, brick dust, and building demolish dust are given in Tables 1(a) and 1(b). Each material is mixed as $10 \%$ and $30 \%$ of total soil weight, respectively. Properties of soil and these soil dust mixtures are also given in Table $1(\mathrm{c})$. In the table " $\mathrm{S}+10 \% \mathrm{WD}$ " is used to denote soil mix with $10 \%$ saw dust. Similarly, "S + 10\% SD," "S $+10 \% \mathrm{BD}$," "S + 10\% DD," "S + 30\% WD," "S + 30\% SD," "S + $30 \% \mathrm{BD}$," and "S + 30\% DD" are used to denote soil mix with $10 \%$ stone dust, soil mix with $10 \%$ brick dust, soil mix with 


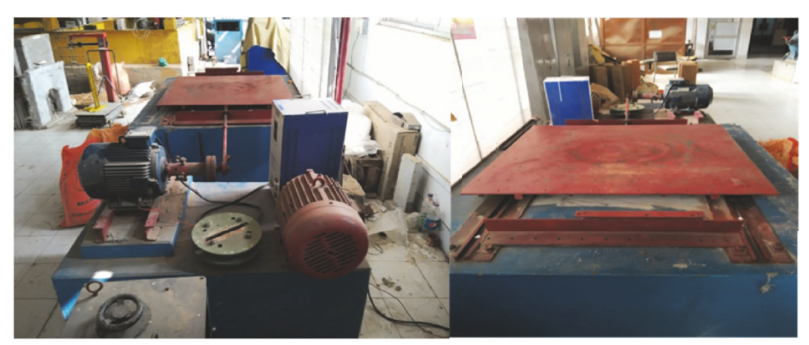

(a) Shake table instrument set-up

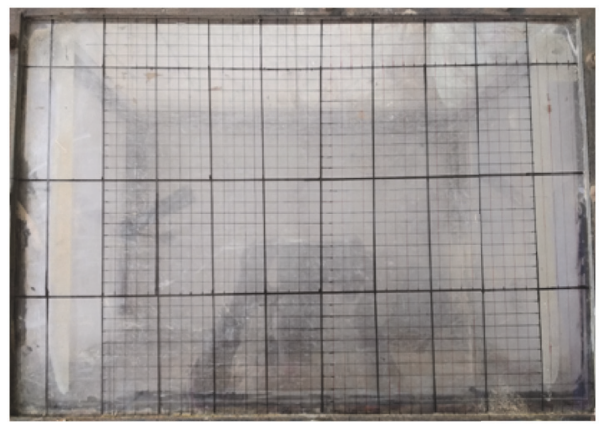

(b) Perspex box with thin marking

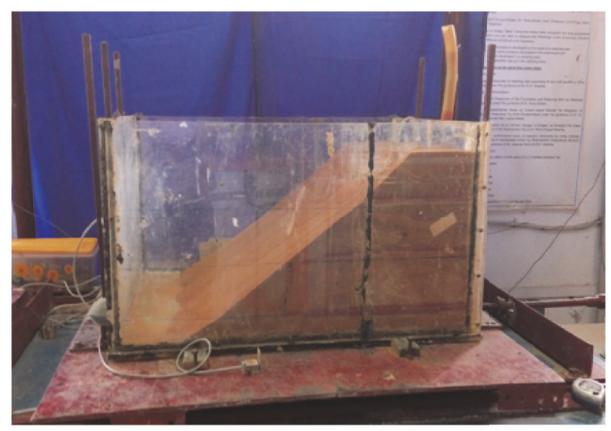

(c) Model slope

FIGURE 1: Instrumentation and preparation of slope model.

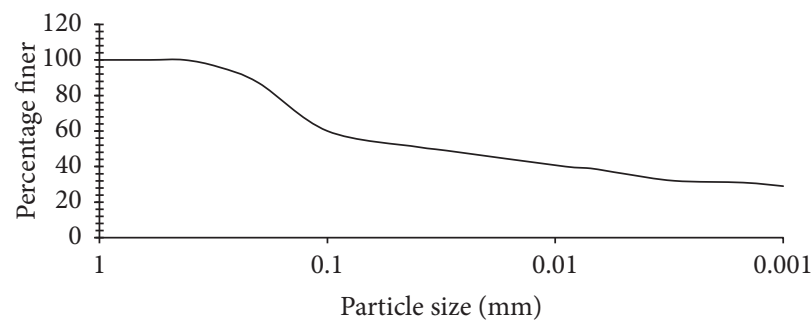

(a)

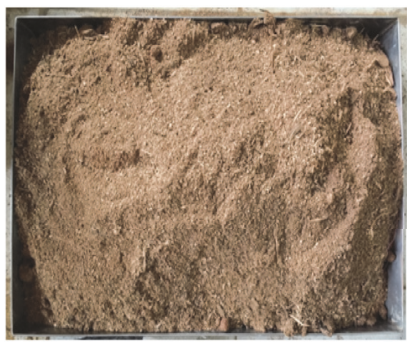

(i) Saw dust

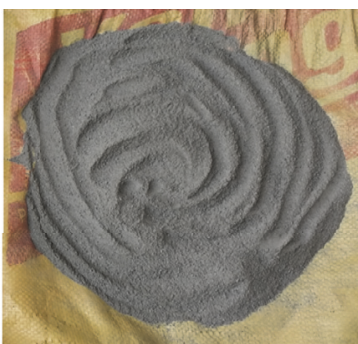

(ii) Stone dust

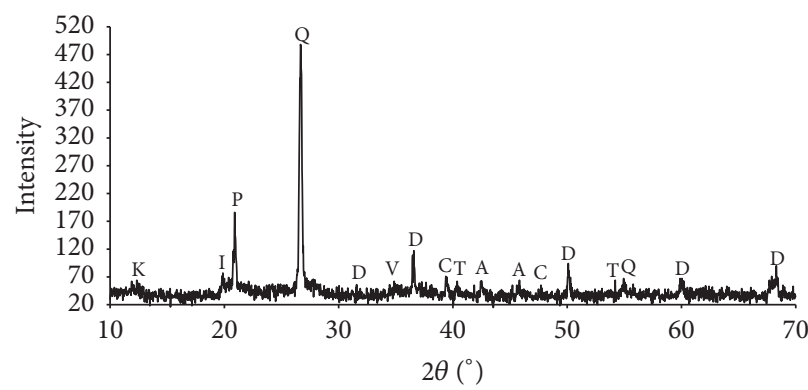

(b) K-Kaolinite, I-Illite, P-Palygorskite, Q-Quartz, D-Dolomite, VVermiculite, C-Calcite, T-Talc, and A- Aragonite

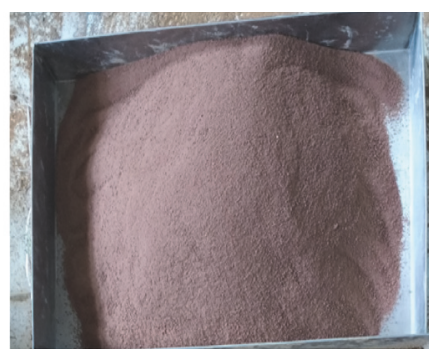

(iii) Brick dust

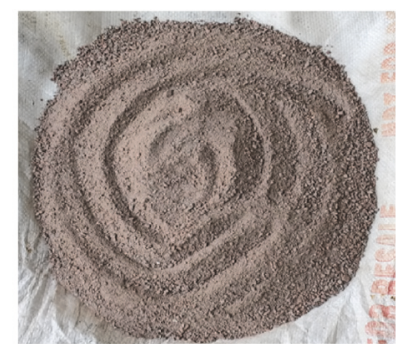

(iv) Building demolish dust

(c)

FIgURE 2: (a) Particle size distribution of soil; (b) XRD diagram of soil used in the present study; (c) Waste dust used to enhance soil strength. 


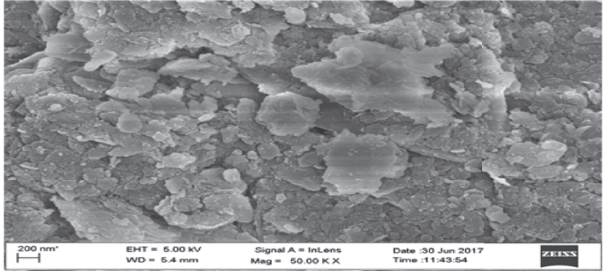

(a)

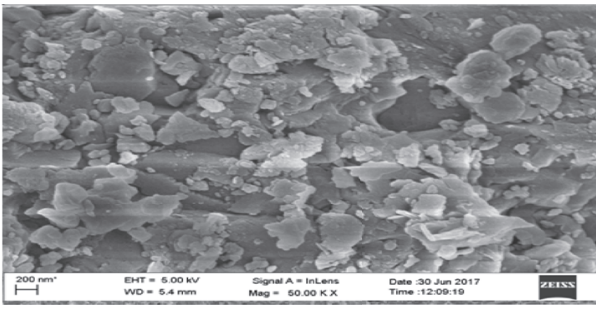

(c)

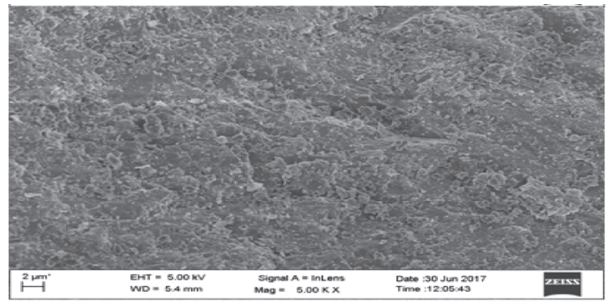

(e)

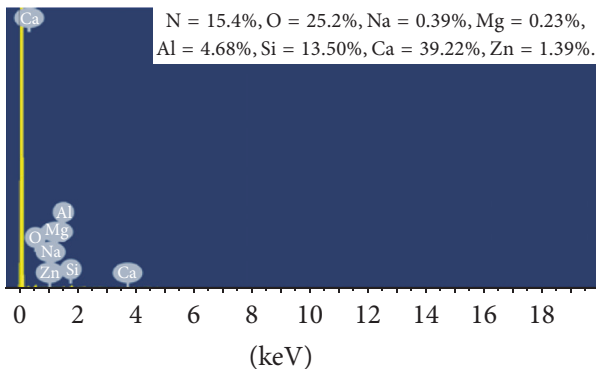

Full Scale 1000 cts Cursor: 0.000

(g)

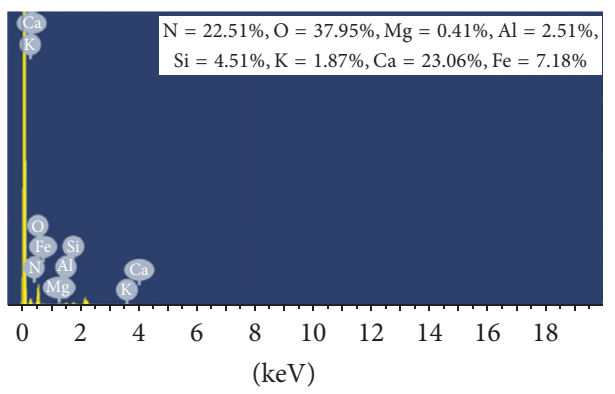

Full Scale 1000 cts Cursor: 0.000

(i)

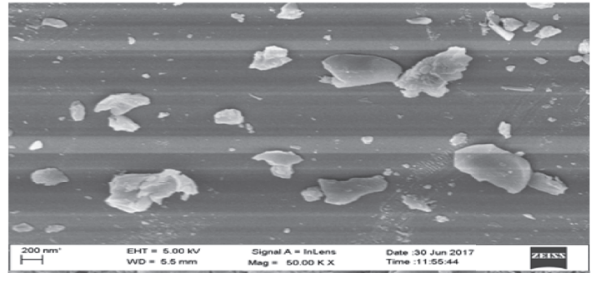

(b)

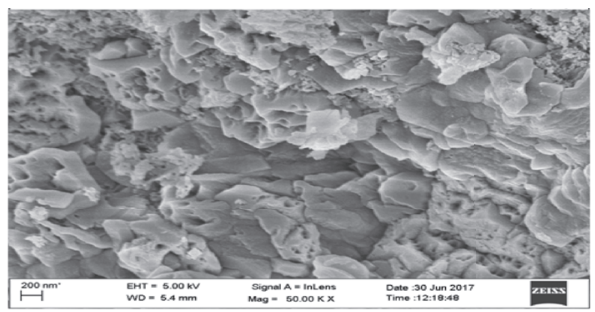

(d)

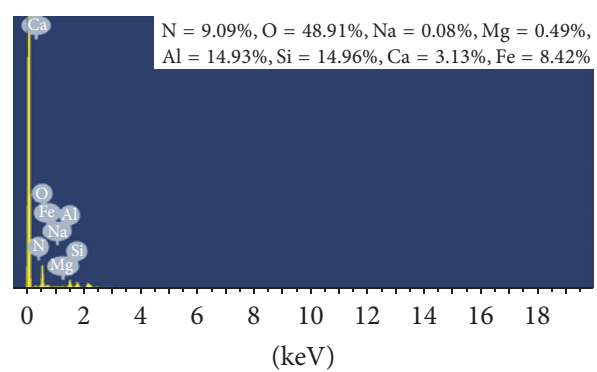

Full Scale 1350 cts Cursor: 0.000

(f)

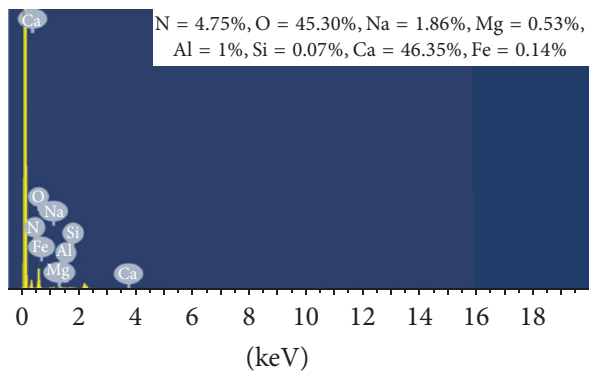

Full Scale 1080 cts Cursor: 0.000

(h)

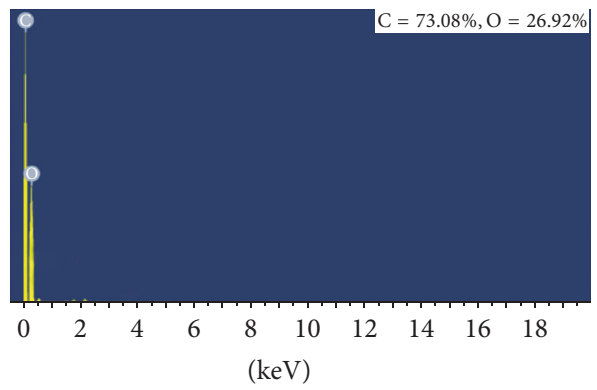

Full Scale 1000 cts Cursor: 0.000

(j)

FIGURE 3: (a)-(e) SEM images of soil, brick dust, stone dust, building demolish dust, and saw dust, respectively, and (f)-(j) EDX patterns of soil, brick dust, stone dust, building demolish dust, and saw dust, respectively. 
TABLE 1

(a) Gradation of different dust mixed with soil

\begin{tabular}{|c|c|c|c|c|c|}
\hline \multicolumn{3}{|c|}{ Weight of sample taken } & \multirow{2}{*}{ Cumulative percentage retained } & \multirow{2}{*}{ Percentage passing } & \multirow{2}{*}{ Remarks } \\
\hline IS sieve size & Weight retained (gm) & Percentage retained & & & \\
\hline \multicolumn{6}{|c|}{ ( } \\
\hline $4.75 \mathrm{~mm}$ & 0 & 0 & 0 & 100.0 & \multirow{8}{*}{$\begin{array}{l}\text { The gradation of } \\
\text { stone dust is zone IV } \\
\text { as per IS: } 383-1970\end{array}$} \\
\hline $2.36 \mathrm{~mm}$ & 0 & 0 & 0 & 100.0 & \\
\hline $1.18 \mathrm{~mm}$ & 04 & 0.4 & 0.4 & 99.6 & \\
\hline $425 \mu$ & 456 & 45.6 & 46 & 53.6 & \\
\hline $300 \mu$ & 428 & 42.8 & 88.8 & 11.2 & \\
\hline $150 \mu$ & 100 & 10 & 98.8 & 1.2 & \\
\hline $75 \mu$ & 10 & 1 & 99.8 & 0.2 & \\
\hline Pan & 02 & 0.2 & 100 & 0 & \\
\hline \multicolumn{6}{|c|}{ Brick dust } \\
\hline $4.75 \mathrm{~mm}$ & 0 & 0 & 0 & 100.0 & \multirow{8}{*}{$\begin{array}{l}\text { The gradation of brick } \\
\text { dust is zone IV as per } \\
\text { IS: } 383-1970\end{array}$} \\
\hline $2.36 \mathrm{~mm}$ & 0 & 0 & 0 & 100.0 & \\
\hline $1.18 \mathrm{~mm}$ & 02 & 0.2 & 0.2 & 99.8 & \\
\hline $425 \mu$ & 454 & 45.4 & 45.6 & 54.4 & \\
\hline $300 \mu$ & 426 & 42.6 & 88.2 & 11.8 & \\
\hline $150 \mu$ & 100 & 10 & 98.2 & 1.8 & \\
\hline $75 \mu$ & 10 & 1 & 99.2 & 0.8 & \\
\hline Pan & 08 & 0.8 & 100 & 0 & \\
\hline \multicolumn{6}{|c|}{ Building demolish dust } \\
\hline $4.75 \mathrm{~mm}$ & 0 & 0 & 0 & 100.0 & \multirow{8}{*}{$\begin{array}{l}\text { The gradation of } \\
\text { building demolish } \\
\text { dust is zone IV as per } \\
\text { IS: } 383-1970\end{array}$} \\
\hline $2.36 \mathrm{~mm}$ & 0 & 0 & 0 & 100.0 & \\
\hline $1.18 \mathrm{~mm}$ & 06 & 0.6 & 0.6 & 99.6 & \\
\hline $425 \mu$ & 454 & 45.4 & 46 & 53.6 & \\
\hline $300 \mu$ & 429 & 42.9 & 88.9 & 11.2 & \\
\hline $150 \mu$ & 98 & 9.8 & 98.7 & 1.2 & \\
\hline $75 \mu$ & 8 & 0.8 & 99.5 & 0.2 & \\
\hline Pan & 05 & 0.5 & 100 & 0 & \\
\hline
\end{tabular}

(b) Physical properties of dust types mixed with soil

\begin{tabular}{|c|c|c|c|}
\hline \multirow{2}{*}{ Tests performed } & \multicolumn{3}{|c|}{ Test results } \\
\hline & Stone dust & Brick dust & Building demolish dust \\
\hline Specific gravity & 2.7 & 1.89 & 2.2 \\
\hline Bulk density & $18.1 \mathrm{kN} / \mathrm{m}^{3}$ & $13.7 \mathrm{kN} / \mathrm{m}^{3}$ & $15.5 \mathrm{kN} / \mathrm{m}^{3}$ \\
\hline Water absorption & $2.6 \%$ & $6.67 \%$ & $3.8 \%$ \\
\hline
\end{tabular}

(c) Properties of slope material

\begin{tabular}{|c|c|c|c|c|c|c|c|}
\hline \multirow{2}{*}{$\begin{array}{l}\text { Slope } \\
\text { material }\end{array}$} & \multicolumn{6}{|c|}{ Material Property } & \multirow[b]{2}{*}{$\begin{array}{c}\text { Internal } \\
\text { friction angle }\end{array}$} \\
\hline & Liquid limit & Plastic limit & $\begin{array}{l}\text { Shrinkage } \\
\text { limit }\end{array}$ & $\begin{array}{l}\text { Unit weight } \\
\left(\mathrm{kN} / \mathrm{m}^{3}\right)\end{array}$ & $\begin{array}{l}\text { Optimum moisture content } \\
\text { (OMC) }\end{array}$ & $\begin{array}{l}\text { Cohesion } \\
\left(\mathrm{kN} / \mathrm{m}^{2}\right)\end{array}$ & \\
\hline Soil & $33 \%$ & $24 \%$ & $16 \%$ & 19.5 & $18 \%$ & 18 & $16^{\circ}$ \\
\hline$S+10 \% \mathrm{WD}$ & $33.2 \%$ & $24.4 \%$ & $16.2 \%$ & 20.5 & $17.6 \%$ & 20 & $16.2^{\circ}$ \\
\hline$S+10 \% S D$ & $33.5 \%$ & $24.8 \%$ & $16.28 \%$ & 19.1 & $15 \%$ & 18.2 & $18^{\circ}$ \\
\hline $\mathrm{S}+10 \% \mathrm{BD}$ & $33.8 \%$ & $25 \%$ & $16.29 \%$ & 18.6 & $14.6 \%$ & 18.35 & $18.5^{\circ}$ \\
\hline $\mathrm{S}+10 \% \mathrm{DD}$ & $34 \%$ & $25.3 \%$ & $17 \%$ & 18.3 & $14.2 \%$ & 18.5 & $19.3^{\circ}$ \\
\hline
\end{tabular}


(c) Continued.

\begin{tabular}{|c|c|c|c|c|c|c|c|}
\hline \multirow{2}{*}{$\begin{array}{l}\text { Slope } \\
\text { material }\end{array}$} & \multicolumn{6}{|c|}{ Material Property } & \multirow[b]{2}{*}{$\begin{array}{c}\text { Internal } \\
\text { friction angle }\end{array}$} \\
\hline & Liquid limit & Plastic limit & $\begin{array}{l}\text { Shrinkage } \\
\text { limit }\end{array}$ & $\begin{array}{l}\text { Unit weight } \\
\left(\mathrm{kN} / \mathrm{m}^{3}\right)\end{array}$ & $\begin{array}{l}\text { Optimum moisture content } \\
\text { (OMC) }\end{array}$ & $\begin{array}{l}\text { Cohesion } \\
\left(\mathrm{kN} / \mathrm{m}^{2}\right)\end{array}$ & \\
\hline $\mathrm{S}+30 \% \mathrm{WD}$ & $34.8 \%$ & $25.4 \%$ & $17.3 \%$ & 18 & $13.8 \%$ & 22 & $17^{\circ}$ \\
\hline$S+30 \% S D$ & $35 \%$ & $25.6 \%$ & $17.6 \%$ & 17.4 & $13.6 \%$ & 20.6 & $21.4^{\circ}$ \\
\hline $\mathrm{S}+30 \% \mathrm{BD}$ & $35.3 \%$ & $25.7 \%$ & $17.8 \%$ & 16 & $13 \%$ & 21.5 & $22.5^{\circ}$ \\
\hline $\mathrm{S}+30 \% \mathrm{DD}$ & $35.8 \%$ & $26 \%$ & $18 \%$ & 15 & $12.5 \%$ & 21.8 & $25^{\circ}$ \\
\hline
\end{tabular}

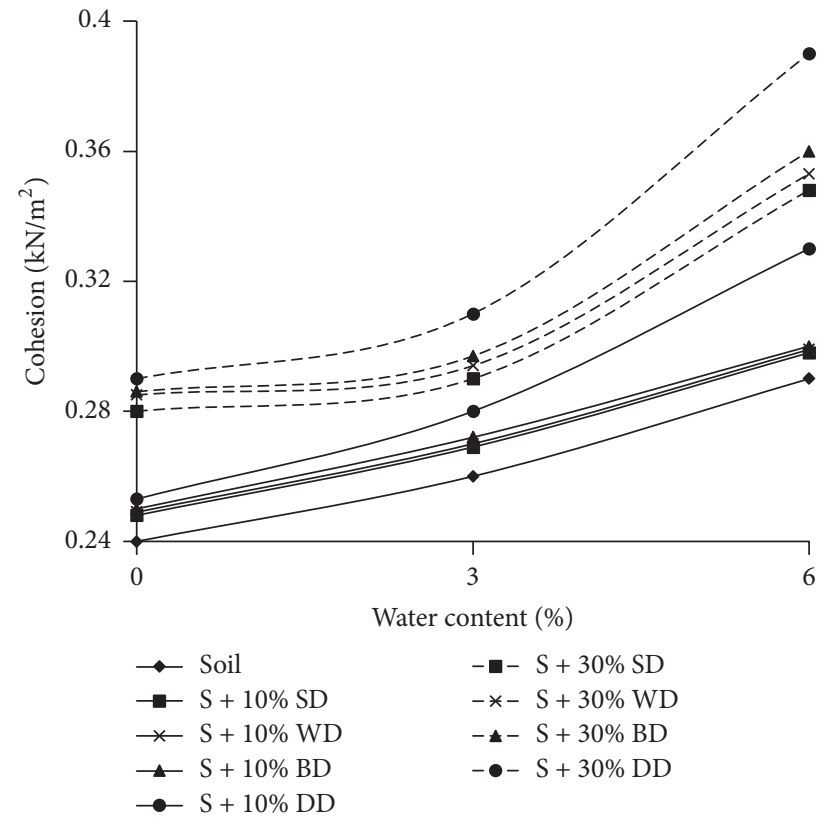

(a) Cohesion of soil and soil dust mixture

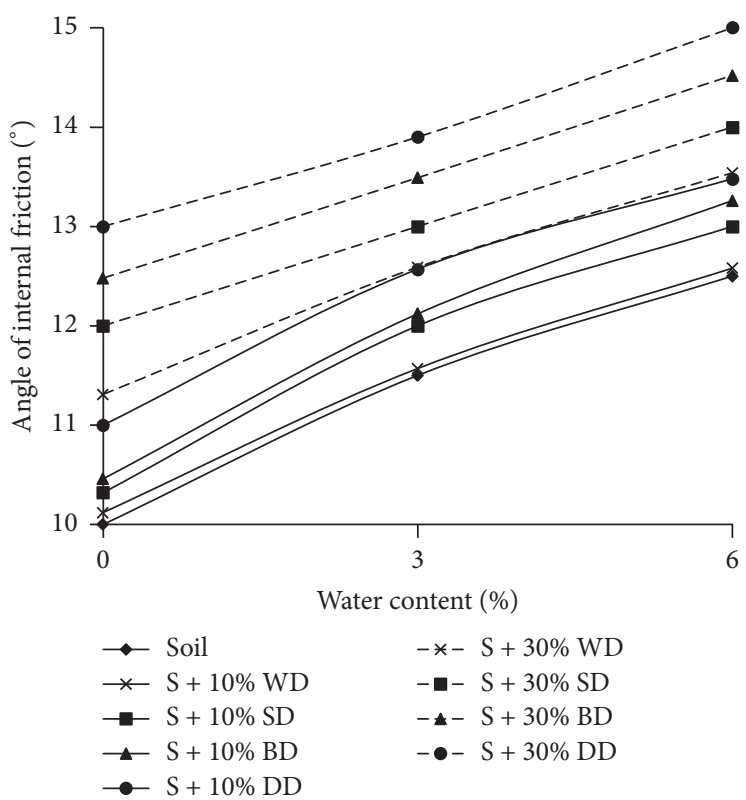

(b) Internal friction angle of soil and soil dust mixture

FIgURE 4: Shear strength parameters of soil and soil dust mixtures at different water content.

$10 \%$ building demolish dust, soil mix with $30 \%$ saw dust, soil mix with $30 \%$ stone dust, soil mix with $30 \%$ brick dust, and soil mix with $30 \%$ building demolish dust, respectively. Shear strength parameters of soil mixture with various dust types at different water content are presented in Figure 4.

2.3. Model Construction and Testing. Slope models are constructed with the soil and soil dust composition as given in Table 1(c) at three different water level conditions for each model such as (1) air dried, (2) at 3\% water content, and (3) at $6 \%$ water content. To maintain the slope geometry for all model slopes the densities of filled slope material composed of "soil," "S + 10\% SD," "S + 10\% BD," "S + 10\% $\mathrm{DD}$," "S + 30\% SD," "S + 30\% BD," and "S + 30\% DD" are found to be $10 \mathrm{kN} / \mathrm{m}^{3}, 11 \mathrm{kN} / \mathrm{m}^{3}$, and $12 \mathrm{kN} / \mathrm{m}^{3}$ at air dried condition, at $3 \%$ water content, and at $6 \%$ water content, respectively. As saw dust has more volume in comparison to other dust types for a particular weight, densities for slope material composed of "S $+10 \% \mathrm{WD}$ " are found to be $8 \mathrm{kN} / \mathrm{m}^{3}$, $9 \mathrm{kN} / \mathrm{m}^{3}$, and $10 \mathrm{kN} / \mathrm{m}^{3}$ and for slope material composed of "S + 30\% WD" are found to be $6 \mathrm{kN} / \mathrm{m}^{3}, 7 \mathrm{kN} / \mathrm{m}^{3}$, and $8 \mathrm{kN} / \mathrm{m}^{3}$, at air dried condition, at $3 \%$ water content, and at $6 \%$ water content, respectively, for construction of model slopes having predefined geometry. Slope models with slope inclination angles $30^{\circ}, 45^{\circ}$, and $60^{\circ}$ are prepared using each mixture separately. A rainfall falling system is used for uniform filling of soil in the Perspex box and model slopes are prepared. A rectangular mixture model is first prepared pouring the mixture in three layers from the hopper. First layer of soil is filled in the box and compacted lightly over the surface to maintain the layer thickness uniform. Similarly second layer and third layer filling are done. After that, one side of the rectangular soil wedge which is supported by a wooden board is slightly removed and slope with desired angle is constructed. To maintain the uniform sloping face and leveled top surface the tamping of the sloping face and top surface is done using wooden block of negligible weight. It is assumed that due to the tamping there is no change in the density and other related parameters of the filled up soil and soil dust mixture.

For convenience the Perspex glass sheet box is marked so that it can represent a graph sheet with origin at extreme right bottom corner and according to the precalculated dimension slope models are shaped with base width " $B=60 \mathrm{~cm}$," height 


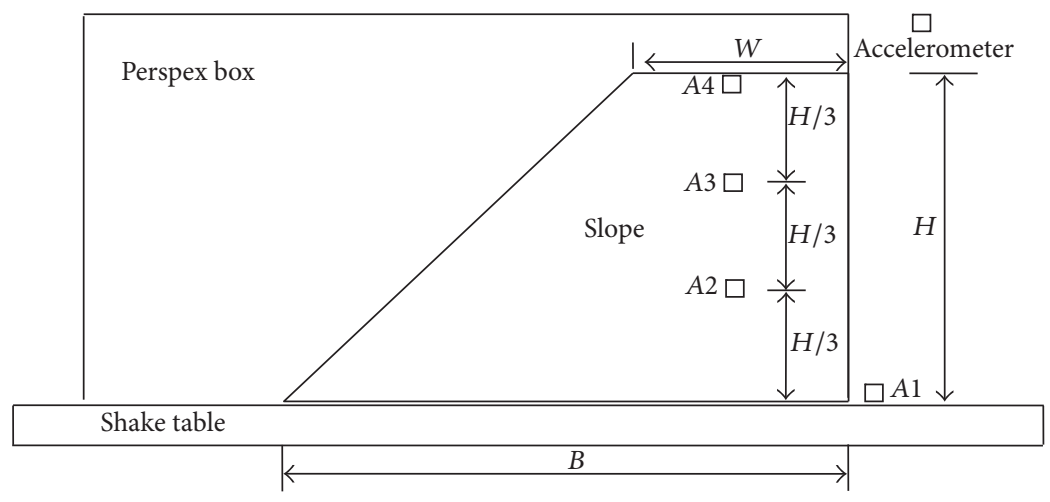

FIGURE 5: Schematic diagram of typical slope with instrumentation.

" $H=25 \mathrm{~cm}$," and top width " $W=17 \mathrm{~cm}$ " for model slope having inclination $30^{\circ}$; " $B=45 \mathrm{~cm}$," " $H=25 \mathrm{~cm}$," and " $W$ $=20 \mathrm{~cm}$ " for model slope having $45^{\circ}$ inclination; and " $B=$ $45 \mathrm{~cm}$," " $H=25 \mathrm{~cm}$," and " $W=30 \mathrm{~cm}$ " for model slope having $60^{\circ}$ with the help of trowel. Accelerometers are of analog voltage output type with full scale acceleration range of $\pm 1 \mathrm{~g}$ along both the $x$ - and $y$-axes, with sensitivity of $0.001 \mathrm{~g}$ placed along the model slope height at distances $H / 3,2 H / 3$, and $H$ from base as shown in Figure 5. After modeling the whole set-up horizontal sinusoidal input motion at two different frequencies is generated to observe responses of each model slope. First, input motion with $2 \mathrm{~Hz}$ frequency and base acceleration $0.2 \mathrm{~g}$ is imposed for duration of 10 second on each model slope and responses are observed. After that, input motion with $5 \mathrm{~Hz}$ frequency and base acceleration $0.2 \mathrm{~g}$ is generated and responses of slope models are observed. Slope models are prepared with soil and soil dust mixtures at different water content and subjected to sinusoidal horizontal input motion at two different frequencies to conduct the study and responses are observed. These tests are devised to understand the effects of acceleration and frequency of base shaking, geometry of the slope, and slope material on the performance of the slope during seismic excitation. The frequency of motion varied from $2 \mathrm{~Hz}$ to $5 \mathrm{~Hz}$ keeping a constant base acceleration of $0.2 \mathrm{~g}$. Table 2 shows various test parameters used for different tests.

\section{Pseudodynamic Analysis of Slope}

It has been observed from these entire tests that model slopes deform after the loading duration and the failure surface is almost planer failure surface. Therefore, pseudodynamic analysis of slope assuming planer failure surface is done to evaluate the sliding displacement of base of slope and is compared to observe horizontal displacements of model slope for different condition.

A slope model of $c-\phi$ soil of height $H$ and slope angle $i$ as shown in Figure 6 is considered. Seismic inertia forces acting on the slope are $Q_{h}(t)$ in the horizontal direction and $Q_{v}(t)$ in vertical direction. $A B$ is the planar failure wedge inclined at an angle $\alpha$ with the horizontal. $R$ is the reaction acting on failure wedge at an angle $\phi_{m}$ with the normal of the failure

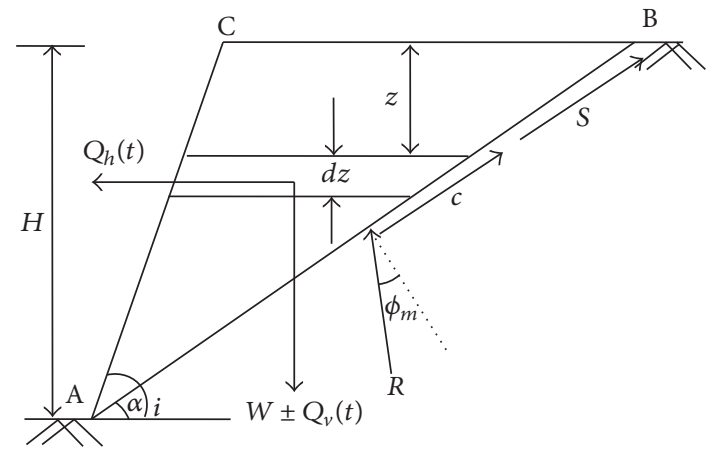

FIgURE 6: Forces on soil wedge.

wedge. $c=c_{m} L$ is the mobilized cohesion acting along the face $\mathrm{AB}$ (length $L$ ) and $\phi_{m}$ is the mobilized internal friction angle.

Weight of the wedge is as follows:

$$
W=\frac{\gamma \times H^{2}(\cot \alpha-\cot i)}{2} .
$$

The mass of a thin element of wedge at depth $z$ of thickness $d z$ is given by

$$
m(z)=\frac{\gamma}{g} \times(\cot \alpha-\cot i) \times(H-z) \times d z .
$$

For a sinusoidal base shaking subjected to both horizontal and vertical earthquake acceleration with amplitude $k_{h} g$ and $k_{v} g$, the horizontal and vertical acceleration, respectively, at any depth $z$ below the ground surface at time " $t$ " can be expressed as

$$
\begin{aligned}
& a_{h}(z, t)=k_{h} \times \sin \omega\left(t-\frac{H-z}{V_{s}}\right) \\
& a_{v}(z, t)=k_{v} \times \sin \omega\left(t-\frac{H-z}{V_{p}}\right) .
\end{aligned}
$$


TABLE 2: Parameters in shaking table test of slope models.

\begin{tabular}{|c|c|c|c|c|c|}
\hline Sl number & Test code & Frequency $(\mathrm{Hz})$ & Slope material & Water content $(\%)$ & Slope inclination \\
\hline$(1)$ & Soil & 2,5 & Soil & Air dried, 3, 6 & $30^{\circ}, 45^{\circ}, 60^{\circ}$ \\
\hline (2) & $S+10 \% \mathrm{WD}$ & 2,5 & Soil and $10 \%$ saw dust of soil weight & Air dried, 3, 6 & $30^{\circ}, 45^{\circ}, 60^{\circ}$ \\
\hline (3) & $\mathrm{S}+10 \% \mathrm{SD}$ & 2,5 & Soil and $10 \%$ stone dust of soil weight & Air dried, 3, 6 & $30^{\circ}, 45^{\circ}, 60^{\circ}$ \\
\hline (4) & $\mathrm{S}+10 \% \mathrm{BD}$ & 2,5 & Soil and $10 \%$ brick dust of soil weight & Air dried, 3, 6 & $30^{\circ}, 45^{\circ}, 60^{\circ}$ \\
\hline (5) & $\mathrm{S}+10 \% \mathrm{DD}$ & 2,5 & Soil and $10 \%$ building demolish dust of soil weight & Air dried, 3, 6 & $30^{\circ}, 45^{\circ}, 60^{\circ}$ \\
\hline (6) & $\mathrm{S}+30 \% \mathrm{WD}$ & 2,5 & Soil and $30 \%$ saw dust of soil weight & Air dried, 3,6 & $30^{\circ}, 45^{\circ}, 60^{\circ}$ \\
\hline (7) & $\mathrm{S}+30 \% \mathrm{SD}$ & 2,5 & Soil and $30 \%$ stone dust of soil weight & Air dried, 3, 6 & $30^{\circ}, 45^{\circ}, 60^{\circ}$ \\
\hline (8) & $\mathrm{S}+30 \% \mathrm{BD}$ & 2,5 & Soil and $30 \%$ brick dust of soil weight & Air dried, 3, 6 & $30^{\circ}, 45^{\circ}, 60^{\circ}$ \\
\hline (9) & $\mathrm{S}+30 \% \mathrm{DD}$ & 2,5 & Soil and $30 \%$ building demolish dust of soil weight & Air dried, 3, 6 & $30^{\circ}, 45^{\circ}, 60^{\circ}$ \\
\hline
\end{tabular}

Horizontal seismic inertia force acting on soil wedge is

$$
\begin{aligned}
& Q_{h}(t)=\int_{0}^{H} m(z) \cdot a_{h}(z, t) \\
& Q_{h}(t)=\frac{k_{h} \gamma \lambda H(\cot \alpha-\cot i)}{4 \pi^{2}}\left[2 \pi \cos 2 \pi\left(\frac{t}{T}-\frac{H}{\lambda}\right)\right. \\
&\left.+\frac{\lambda}{H}\left\{\sin 2 \pi\left(\frac{t}{T}-\frac{H}{\lambda}\right)-\sin 2 \pi \frac{t}{T}\right\}\right] .
\end{aligned}
$$

Similarly vertical seismic inertia force is

$$
\begin{aligned}
& Q_{v}(t)=\int_{0}^{H} m(z) \cdot a_{v}(z, t) \\
& Q_{v}(t)=\frac{k_{v} \gamma \eta H(\cot \alpha-\cot i)}{4 \pi^{2}}\left[2 \pi \cos 2 \pi\left(\frac{t}{T}-\frac{H}{\eta}\right)\right. \\
&\left.+\frac{\eta}{H}\left\{\sin 2 \pi\left(\frac{t}{T}-\frac{H}{\eta}\right)-\sin 2 \pi \frac{t}{T}\right\}\right] .
\end{aligned}
$$

The resultant weight which makes an angle $\psi^{\prime}$ with vertical and is given as

$$
\psi^{\prime}=\tan ^{-1} \frac{k_{h}}{\left(1 \pm k_{v}\right)} .
$$

Using sine rule:

$$
\begin{aligned}
\frac{W^{\prime}}{\sin \left(90^{\circ}+\phi_{m}\right)} & =\frac{c_{m}}{\sin \left(\alpha+\psi^{\prime}-\phi_{m}\right)} \\
& =\frac{R}{\sin \left(90^{\circ}-\alpha-\psi^{\prime}\right)} .
\end{aligned}
$$

Solving (6) we get

$$
\begin{aligned}
S_{n} & =\frac{c_{m}}{\gamma H}=\frac{\sin \alpha \sin \left(\alpha+\varphi-\phi_{m}\right)(\cot \alpha-\cot i)}{2 \cos \phi_{m}} \times[1 \\
& \pm \frac{\eta k_{v}}{H \pi^{2}}\left\{2 \pi \cos \omega \varepsilon+\frac{\eta}{H}(\sin \omega \varepsilon-\sin \omega t)\right\} \\
& +\frac{\lambda^{2} k_{h}^{2}}{4 \pi^{4} H^{2}}\left\{2 \pi \cos \omega \xi+\frac{\lambda}{H}(\sin \omega \xi-\sin \omega t)\right\}^{2} \\
& \left.+\frac{\eta^{2} k_{v}^{2}}{4 \pi^{4} H^{2}}\left\{2 \pi \cos \omega \varepsilon+\frac{\eta}{H}(\sin \omega \varepsilon-\sin \omega t)\right\}^{2}\right]^{1 / 2}
\end{aligned}
$$

where $\varepsilon=t-H / V_{p}, \xi=t-H / V_{s}$.

Normal force $(N)$ and shear force $(S)$ acting on the soil wedge are expressed as

$$
\begin{aligned}
N & =\left(W \pm Q_{v}(t)+\left(0.5 \gamma H^{2}\right)\right) \cos \alpha-Q_{h}(t) \sin \alpha \\
S & =(C+N \tan \phi) .
\end{aligned}
$$

And shear force $S=(C+N \tan \phi)$ along the failure plane.

Horizontal forces acting on the soil wedge are $S \cos \alpha$, $N \sin \alpha$, and $Q_{h}(t)$.

Factor of safety for unreinforced earth slope is the ratio of resisting force and driving force acting on soil wedge and it is formulated as

$$
\mathrm{Fos}=\frac{(C+N \tan \phi) \cos \alpha}{N \sin \alpha+Q_{h}(t)} .
$$

When the slope is on the verge of failure factor of safety is reduced to unity and the acceleration which reduces this factor of safety is termed as yield acceleration $k_{y}$ as discussed by Chanda et al. [23]. $k_{y}$ is determined for different slope inclination and soil friction angle by equating factor of safety to one and $k_{y}$ is formulated by substituting all terms in (11) and is expressed as

$$
\begin{aligned}
k_{y 1} & =\frac{m_{3}}{m_{4}} \\
\text { or } k_{y 2} & =\frac{m_{3}}{m_{5}} .
\end{aligned}
$$


$k_{y 1}$ and $k_{y 2}$ are evaluated by MATLAB 2012 (a) optimization program which yields lesser value termed as $k_{y}$. In these expressions

$$
\begin{aligned}
m_{1} & =\frac{\gamma \lambda H(\cot \alpha-\cot i)}{4 \pi^{2}}\left[2 \pi \cos 2 \pi\left(\frac{t}{T}-\frac{H}{\lambda}\right)\right. \\
& \left.+\frac{\lambda}{H}\left\{\sin 2 \pi\left(\frac{t}{T}-\frac{H}{\lambda}\right)-\sin 2 \pi \frac{t}{T}\right\}\right] \\
m_{2} & =\frac{\gamma \eta H(\cot \alpha-\cot i)}{4 \pi^{2}}\left[2 \pi \cos 2 \pi\left(\frac{t}{T}-\frac{H}{\eta}\right)\right. \\
& \left.+\frac{\eta}{H}\left\{\sin 2 \pi\left(\frac{t}{T}-\frac{H}{\eta}\right)-\sin 2 \pi \frac{t}{T}\right\}\right] \\
m_{3} & =\left\{\cos \alpha(\sin \alpha-\tan \phi \cos \alpha)\left(W+0.5 \gamma H^{2}\right)\right\}-c \\
& \cdot \cos \alpha \\
m_{4} & =\left(m_{1}\right. \\
& \left.+\left(a_{c} m_{2} \cos \alpha-m_{1} \sin \alpha\right)(\sin \alpha-\tan \phi \cos \alpha)\right) \\
m_{5} & =\left(m_{1}\right. \\
& \left.-\left(a_{c} m_{2} \cos \alpha-m_{1} \sin \alpha\right)(\sin \alpha-\tan \phi \cos \alpha)\right) .
\end{aligned}
$$

$H / \lambda=0.25$ and $H / \eta=0.09, a_{c}=k_{v} / k_{h}$ for horizontal motion only, and $a_{c}=0$ and while applied acceleration is more than yield acceleration the sliding displacement of slope is obtained by double integrating the difference of the applied acceleration and the yield acceleration over time of earthquake excitation and is expressed as

$$
\mathrm{SD}=\int_{0}^{t} \int_{0}^{t}\left(k_{h}-k_{y}\right) g d t .
$$

In the present analysis applied acceleration is assumed to be $k_{h}=0.2 \mathrm{~g}$ as all the model slope in test is subjected to a horizontal base shaking of $0.2 \mathrm{~g}$ acceleration. Strength parameter of model slope material is taken from Figure 4 and for each slope the sliding displacement using pseudodynamic method is determined.

\section{Results and Discussions}

4.1. Acceleration Response on Slopes Subjected to Dynamic Loading. Acceleration-time history plot of 4 accelerometers placed at different elevations of a typical model test is shown in Figure 7. It has been observed that for a typical model slope with $45^{\circ}$ inclination and made up of S $+10 \%$ SD at $3 \%$ water content, the acceleration at different elevation along the slope height $(A 2, A 3$ and $A 4)$ is on an average about 1.15, 1.4, and 1.55 times the base acceleration $(A 1)$, respectively.

Plots presented in Figure 8 show acceleration responses of all model slopes for different slope material, slope inclination angle, and frequency of input motion at air dried condition. For simplification the abscissa in these plots represents the normalized elevation $(h / H)$ and axis represents RMSA amplification factor. Root mean square acceleration (RMSA)

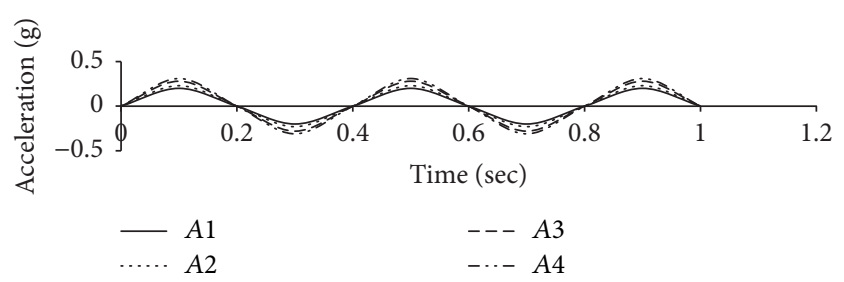

FIgURE 7: Acceleration history of accelerometers placed at different elevation of a typical soil slope with $45^{\circ}$ inclination, frequency $5 \mathrm{~Hz}$.

amplification factor is the ratio of response acceleration value in the soil to that of the corresponding value of the base acceleration (Kramer, 1996, ML). The RMSA value seen in these plots corresponds to the state at the end of $2 \mathrm{~Hz}$ and $5 \mathrm{~Hz}$ shaking for duration of 10 seconds. These plots depict that acceleration amplification at top is to be the most and the values are highly dependent on slope material. As the material strength increases the acceleration RMSA amplification value decreases for a typical slope at typical frequency of input motion. Figures 8(a)-8(f) depict that "RMSA amplification factor" value decreases up to $35.42 \%, 36.36 \%, 33.89 \%, 35.71 \%$, $32.31 \%$, and $28.98 \%$, respectively, when the slope material is changed from soil to "S + 30\% DD" at normalized elevation. Similarly the pattern is also observed for other model slopes under sinusoidal motion and these responses are presented in Table 3. Tabulated result also shows that responses of slope material with higher densities are better than slope material with lower densities for a typical slope at a particular frequency of input motion.

4.2. Horizontal Displacement of Base due to the Effect of Dynamic Loading on Model Slope. Horizontal sinusoidal input motion caused sliding displacement of base. The displacement base ratio $(D / B)$ of model slopes made up of various material mixtures at different water content is presented in tabular form. For three different water content unit weights of slope mass are different and it is reflected from Table 4 that " $D / B$ " is decreasing with increase in water content of the mixture. The table depicts that " $D / B$ " ratio is different for different mixtures. S + 30\% DD mixture has maximum strength and due to this reason for a particular water content and nature of input motion the " $D / B$ " value is minimum when slope is made up of this material. It has been observed from the table that, for slope inclination $30^{\circ}$, “ $D / B$ " value decreases up to $96 \%$, when the slope material is changed from soil to "S $+30 \% \mathrm{DD}$ " at $6 \%$ water content and frequency of input motion $2 \mathrm{~Hz}$. Similarly, other results presented in the table reflect that slope made up soil shows adverse response against dynamic loading and the performance of slope improves gradually from soil to "S + 30\% DD" along with increase in water content of slope material.

4.3. Crest Deformation of Model Slope after Loading. Vertical deformation at crest on all slope models has been observed when the input motion is imposed for certain duration. The crest deformation to slope height ratio $(h / H)$ against water content for different mixtures is observed and presented in 


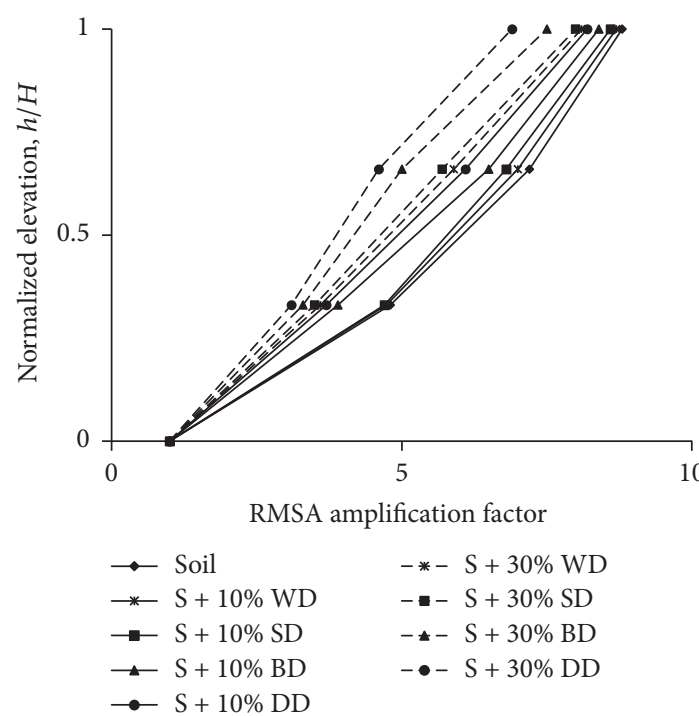

(a) Response of model slope with $30^{\circ}$ inclination at $2 \mathrm{~Hz}$ frequency

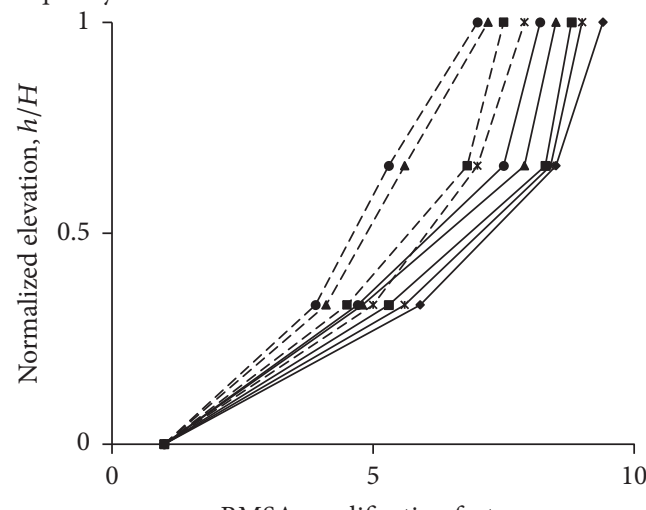

RMSA amplification factor

$$
\begin{array}{ll}
\rightarrow \text { Soil } & -*-S+30 \% \mathrm{WD} \\
\rightarrow \mathrm{S}+10 \% \mathrm{WD} & --\mathrm{S}+30 \% \mathrm{SD} \\
\rightarrow \mathrm{S}+10 \% \mathrm{SD} & --\mathrm{S}+30 \% \mathrm{BD} \\
\rightarrow \mathrm{S}+10 \% \mathrm{BD} & --\mathrm{S}+30 \% \mathrm{DD} \\
\rightarrow-\mathrm{S}+10 \% \mathrm{DD} &
\end{array}
$$

(c) Response of model slope with $60^{\circ}$ inclination at $2 \mathrm{~Hz}$ frequency

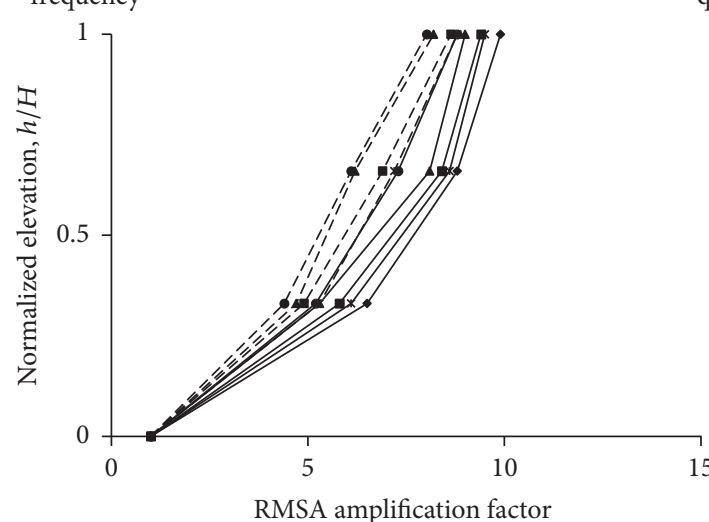

RMSA amplification factor

$$
\begin{array}{ll}
\rightarrow \text { Soil } & -*-\mathrm{S}+30 \% \mathrm{WD} \\
\rightarrow-\mathrm{S}+10 \% \mathrm{WD} & --\mathrm{S}+30 \% \mathrm{SD} \\
\rightarrow \mathrm{S}+10 \% \mathrm{SD} & --\mathrm{S}+30 \% \mathrm{BD} \\
\rightarrow \mathrm{S}+10 \% \mathrm{BD} & --\mathrm{S}+30 \% \mathrm{DD} \\
\rightarrow \mathrm{S}+10 \% \mathrm{DD} &
\end{array}
$$

(e) Response of model slope with $45^{\circ}$ inclination at $5 \mathrm{~Hz}$ frequency

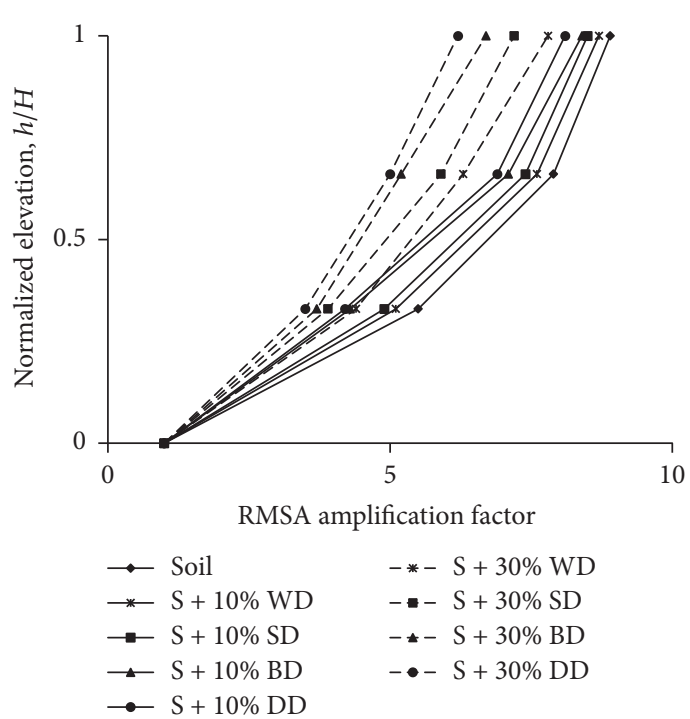

(b) Response of model slope with $45^{\circ}$ inclination at $2 \mathrm{~Hz}$ frequency

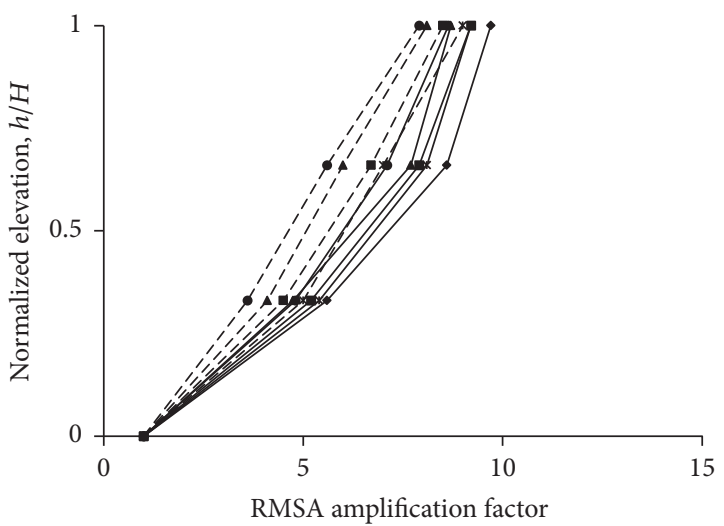

$$
\begin{array}{ll}
\rightarrow \text { Soil } & -*-\mathrm{S}+30 \% \mathrm{WD} \\
\rightarrow \mathrm{S}+10 \% \mathrm{WD} & --\mathrm{S}+30 \% \mathrm{SD} \\
\rightarrow \mathrm{S}+10 \% \mathrm{SD} & --\mathrm{S}+30 \% \mathrm{BD} \\
\rightarrow \mathrm{S}+10 \% \mathrm{BD} & -\bullet \mathrm{S}+30 \% \mathrm{DD} \\
\rightarrow \mathrm{S}+10 \% \mathrm{DD} &
\end{array}
$$

(d) Response of model slope with $30^{\circ}$ inclination at $5 \mathrm{~Hz}$ frequency

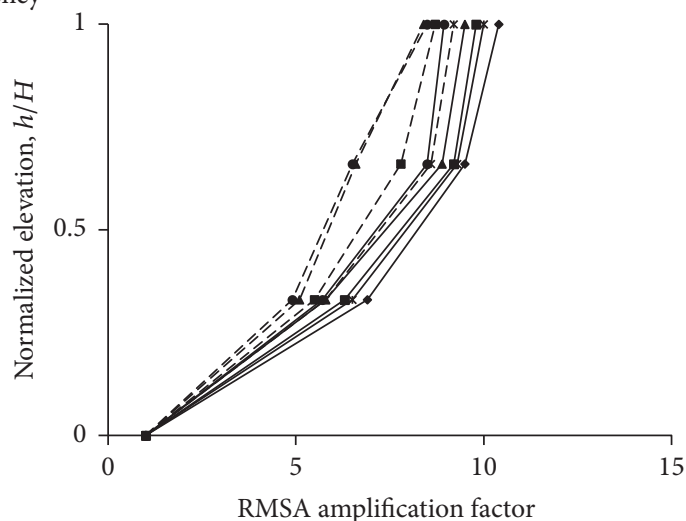

$$
\begin{array}{ll}
\rightarrow \text { Soil } & -*-S+30 \% \mathrm{WD} \\
\rightarrow \mathrm{S}+10 \% \mathrm{WD} & --\mathrm{S}+30 \% \mathrm{SD} \\
\rightarrow \mathrm{S}+10 \% \mathrm{SD} & -\div \mathrm{S}+30 \% \mathrm{BD} \\
\rightarrow \mathrm{S}+10 \% \mathrm{BD} & --\mathrm{S}+30 \% \mathrm{DD} \\
\rightarrow \mathrm{S}+10 \% \mathrm{DD} &
\end{array}
$$

(f) Response of model slope with $60^{\circ}$ inclination at $5 \mathrm{~Hz}$ frequency

FIGURE 8: Response of slope made up of soil and soil dust mixtures at frequency of input motion $2 \mathrm{~Hz}$ and $5 \mathrm{~Hz}$ for air dried material. 


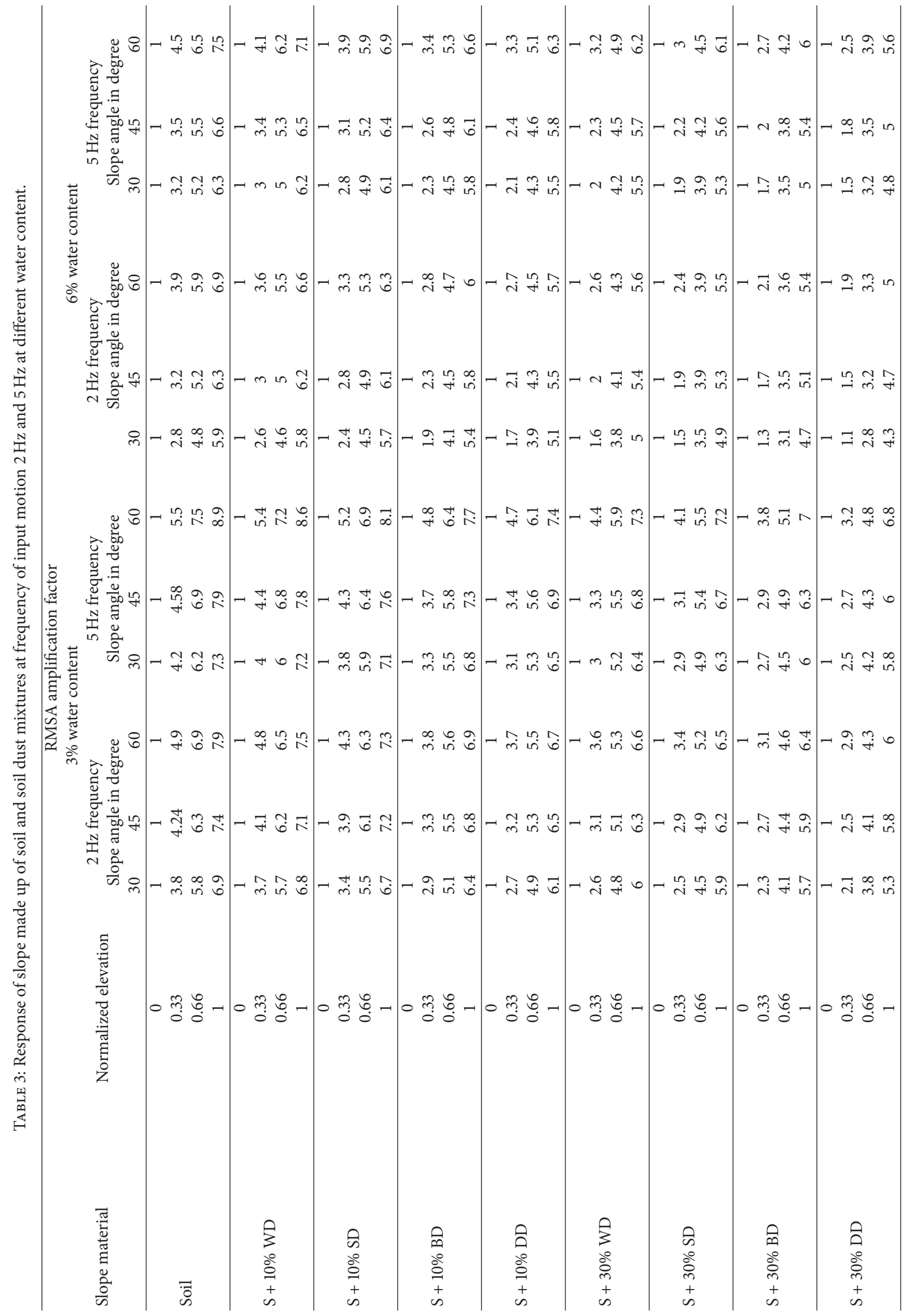


TABLE 4: Response of slope made up of soil and soil dust mixtures in terms of base displacement at frequency of input motion $2 \mathrm{~Hz}$ and $5 \mathrm{~Hz}$.

\begin{tabular}{|c|c|c|c|c|c|c|c|}
\hline \multicolumn{8}{|c|}{ Displacement base ratio $(D / B)$} \\
\hline \multirow{3}{*}{ Slope material } & \multirow{3}{*}{ Water content } & \multicolumn{3}{|c|}{$2 \mathrm{~Hz}$ frequency } & \multicolumn{3}{|c|}{$5 \mathrm{~Hz}$ frequency } \\
\hline & & \multicolumn{3}{|c|}{ Slope angle in degree } & \multicolumn{3}{|c|}{ Slope angle in degree } \\
\hline & & 30 & 45 & 60 & 30 & 45 & 60 \\
\hline \multirow{3}{*}{ Soil } & 0 & 0.16 & 0.23 & 0.28 & 0.17 & 0.26 & 0.31 \\
\hline & 3 & 0.12 & 0.19 & 0.19 & 0.14 & 0.21 & 0.22 \\
\hline & 6 & 0.1 & 0.15 & 0.16 & 0.11 & 0.17 & 0.18 \\
\hline \multirow{3}{*}{$S+10 \% \mathrm{WD}$} & 0 & 0.15 & 0.21 & 0.26 & 0.16 & 0.25 & 0.29 \\
\hline & 3 & 0.11 & 0.17 & 0.16 & 0.12 & 0.19 & 0.19 \\
\hline & 6 & 0.09 & 0.13 & 0.15 & 0.1 & 0.15 & 0.171 \\
\hline \multirow{3}{*}{$S+10 \% S D$} & 0 & 0.13 & 0.2 & 0.24 & 0.16 & 0.25 & 0.28 \\
\hline & 3 & 0.1 & 0.15 & 0.16 & 0.12 & 0.19 & 0.185 \\
\hline & 6 & 0.08 & 0.12 & 0.14 & 0.09 & 0.15 & 0.165 \\
\hline \multirow{3}{*}{$S+10 \% B D$} & 0 & 0.11 & 0.17 & 0.2 & 0.15 & 0.22 & 0.25 \\
\hline & 3 & 0.08 & 0.104 & 0.12 & 0.11 & 0.14 & 0.156 \\
\hline & 6 & 0.06 & 0.08 & 0.1 & 0.09 & 0.11 & 0.125 \\
\hline \multirow{3}{*}{$S+10 \% \mathrm{DD}$} & 0 & 0.08 & 0.13 & 0.15 & 0.13 & 0.19 & 0.203 \\
\hline & 3 & 0.06 & 0.075 & 0.09 & 0.08 & 0.11 & 0.119 \\
\hline & 6 & 0.04 & 0.05 & 0.064 & 0.05 & 0.08 & 0.085 \\
\hline \multirow{3}{*}{$\mathrm{S}+30 \% \mathrm{WD}$} & 0 & 0.07 & 0.11 & 0.13 & 0.11 & 0.18 & 0.18 \\
\hline & 3 & 0.05 & 0.061 & 0.08 & 0.07 & 0.098 & 0.105 \\
\hline & 6 & 0.02 & 0.04 & 0.04 & 0.03 & 0.054 & 0.064 \\
\hline \multirow{3}{*}{$S+30 \% S D$} & 0 & 0.06 & 0.09 & 0.11 & 0.10 & 0.17 & 0.16 \\
\hline & 3 & 0.04 & 0.048 & 0.05 & 0.07 & 0.096 & 0.0747 \\
\hline & 6 & 0.013 & 0.02 & 0.02 & 0.02 & 0.04 & 0.034 \\
\hline \multirow{3}{*}{$\mathrm{S}+30 \% \mathrm{BD}$} & 0 & 0.04 & 0.07 & 0.08 & 0.08 & 0.16 & 0.12 \\
\hline & 3 & 0.02 & 0.03 & 0.04 & 0.04 & 0.075 & 0.061 \\
\hline & 6 & 0.009 & 0.013 & 0.02 & 0.02 & 0.025 & 0.024 \\
\hline \multirow{3}{*}{$\mathrm{S}+30 \% \mathrm{DD}$} & 0 & 0.03 & 0.05 & 0.07 & 0.07 & 0.134 & 0.117 \\
\hline & 3 & 0.01 & 0.017 & 0.02 & 0.02 & 0.064 & 0.033 \\
\hline & 6 & 0.004 & 0.01 & 0.01 & 0.01 & 0.018 & 0.016 \\
\hline
\end{tabular}

Table 5. It has been seen from table that " $h / H$ " ratio decreases about $46 \%$ when the slope material is changed from soil to "S $+30 \% \mathrm{DD}$ " at air dried condition for a slope inclination $30^{\circ}$. Similarly the gradual increase of strength from soil to different soil mixtures for a particular water content and nature of input motion has also depicted from the tabulated result.

4.4. Evaluation of Critical Angle of Failure Plane with Horizontal from Pseudodynamic Analysis of Slope. For a stable condition the stability number of slope must be low. Eqn. (9) is solved using MATLAB 2012(a) and the critical $\alpha$ value $\left(\alpha_{c}\right)$, that is, inclination of failure surface with horizontal corresponding to maximum stability number for each slope at different soil condition, is evaluated. Table 6 shows the value of $\alpha_{c}$ and $S_{n}$ for a model slope made up of $S+10 \%$ WD at different slope inclination and internal friction angle of mixture.

\section{Comparison}

The deformed slope geometry after both experimental and analytical studies subjected to horizontal sinusoidal vibration for slope material made up of soil and 30\% stone dust at $6 \%$ water content is presented in Figure 9 and it has been observed that the failure line in experimental study is slightly lower than analytical one. The reason may be the limitations of small model text in laboratory under certain boundary condition.

Solving (14) sliding displacement of model slope by pseudodynamic method is evaluated and compared with sliding displacement observed on model slope under shake table test. Table 7 shows the analytical and experimental 
TABLE 5: Response of slope made up of soil and soil dust mixtures in terms of crest deformation at frequency of input motion $2 \mathrm{~Hz}$ and $5 \mathrm{~Hz}$.

\begin{tabular}{|c|c|c|c|c|c|c|c|}
\hline \multicolumn{8}{|c|}{ Crest deformation to slope height ratio $(h / H)$} \\
\hline \multirow{3}{*}{ Slope material } & \multirow{3}{*}{ Water content } & \multirow{2}{*}{\multicolumn{3}{|c|}{$\begin{array}{c}2 \mathrm{~Hz} \text { frequency } \\
\text { Slope angle in degree }\end{array}$}} & \multirow{2}{*}{\multicolumn{3}{|c|}{$\begin{array}{c}5 \mathrm{~Hz} \text { frequency } \\
\text { Slope angle in degree }\end{array}$}} \\
\hline & & & & & & & \\
\hline & & 30 & 45 & 60 & 30 & 45 & 60 \\
\hline \multirow{3}{*}{ Soil } & 0 & 0.26 & 0.3 & 0.36 & 0.3 & 0.34 & 0.4 \\
\hline & 3 & 0.215 & 0.26 & 0.32 & 0.24 & 0.3 & 0.36 \\
\hline & 6 & 0.16 & 0.2 & 0.26 & 0.2 & 0.24 & 0.3 \\
\hline \multirow{3}{*}{$\mathrm{S}+10 \% \mathrm{WD}$} & 0 & 0.25 & 0.29 & 0.35 & 0.29 & 0.33 & 0.39 \\
\hline & 3 & 0.2 & 0.25 & 0.31 & 0.22 & 0.29 & 0.35 \\
\hline & 6 & 0.15 & 0.19 & 0.245 & 0.19 & 0.23 & 0.29 \\
\hline \multirow{3}{*}{$S+10 \% S D$} & 0 & 0.24 & 0.28 & 0.34 & 0.28 & 0.32 & 0.38 \\
\hline & 3 & 0.193 & 0.24 & 0.3 & 0.215 & 0.28 & 0.34 \\
\hline & 6 & 0.14 & 0.18 & 0.24 & 0.18 & 0.22 & 0.28 \\
\hline \multirow{3}{*}{$S+10 \% \mathrm{BD}$} & 0 & 0.225 & 0.26 & 0.32 & 0.26 & 0.3 & 0.36 \\
\hline & 3 & 0.175 & 0.22 & 0.28 & 0.19 & 0.26 & 0.32 \\
\hline & 6 & 0.12 & 0.16 & 0.22 & 0.16 & 0.2 & 0.26 \\
\hline \multirow{3}{*}{$S+10 \% \mathrm{DD}$} & 0 & 0.2 & 0.24 & 0.3 & 0.24 & 0.28 & 0.34 \\
\hline & 3 & 0.16 & 0.2 & 0.26 & 0.175 & 0.24 & 0.3 \\
\hline & 6 & 0.11 & 0.14 & 0.2 & 0.14 & 0.18 & 0.24 \\
\hline \multirow{3}{*}{$\mathrm{S}+30 \% \mathrm{WD}$} & 0 & 0.19 & 0.22 & 0.28 & 0.23 & 0.26 & 0.32 \\
\hline & 3 & 0.14 & 0.18 & 0.24 & 0.155 & 0.22 & 0.28 \\
\hline & 6 & 0.105 & 0.12 & 0.18 & 0.13 & 0.15 & 0.22 \\
\hline \multirow{3}{*}{$S+30 \% S D$} & 0 & 0.16 & 0.2 & 0.26 & 0.2 & 0.24 & 0.3 \\
\hline & 3 & 0.13 & 0.16 & 0.22 & 0.13 & 0.2 & 0.26 \\
\hline & 6 & 0.1 & 0.1 & 0.16 & 0.1 & 0.14 & 0.2 \\
\hline \multirow{3}{*}{$\mathrm{S}+30 \% \mathrm{BD}$} & 0 & 0.14 & 0.18 & 0.24 & 0.18 & 0.22 & 0.28 \\
\hline & 3 & 0.11 & 0.14 & 0.2 & 0.12 & 0.18 & 0.24 \\
\hline & 6 & 0.08 & 0.08 & 0.14 & 0.08 & 0.12 & 0.18 \\
\hline \multirow{3}{*}{$\mathrm{S}+30 \% \mathrm{DD}$} & 0 & 0.12 & 0.16 & 0.22 & 0.16 & 0.2 & 0.26 \\
\hline & 3 & 0.09 & 0.12 & 0.18 & 0.1 & 0.16 & 0.22 \\
\hline & 6 & 0.04 & 0.06 & 0.12 & 0.072 & 0.1 & 0.16 \\
\hline
\end{tabular}

TABLE 6: Critical angle and stability number of slope made up of soil $+10 \%$ saw dust.

\begin{tabular}{lccccc}
\hline & \multicolumn{5}{c}{$K_{h}=0.2, K_{v}=0$} \\
$i$ & $S_{n}$ at $\phi=10^{\circ}$ & $\alpha_{c}\left(^{\circ}\right)$ & $S_{n}$ at $\phi=11.5^{\circ}$ & $\alpha_{c}\left(^{\circ}\right)$ & $S_{n}$ at $\phi=12.5^{\circ}$ \\
\hline $10^{\circ}$ & 0.0288 & 7.2 & 0.026 & 8 & 0.023 \\
$20^{\circ}$ & 0.051 & 17.5 & 0.048 & 18 & 0.046 \\
$30^{\circ}$ & 0.075 & 25.6 & 0.073 & 26 & 0.071 \\
$40^{\circ}$ & 0.1 & 36.5 & 0.092 & 37 & 0.089 \\
$50^{\circ}$ & 0.126 & 46.2 & 0.11 & 47 & 0.092 \\
$60^{\circ}$ & 0.155 & 56.2 & 0.14 & 57 & 0.12 \\
\hline
\end{tabular}

results for sliding displacement under horizontal sinusoidal vibration for different model at different water content and unit weight for slope material made up of soil and $30 \%$ stone dust.

\section{Conclusions}

In this present paper an attempt is made to conduct experiment on model slopes made up of soil and soil dust mixtures. An analytical work using pseudodynamic method considering planer rupture surface is also carried out. On the basis of analysis of results in the present investigation, the following conclusions are drawn:

(1) Recorded responses of accelerometers placed at different elevation along slope height reflect that water content of slope material affects slope safety. At normalized elevation 0.33 and frequency of input motion $2 \mathrm{~Hz}$ response of slope with inclination $60^{\circ}$ in terms of RMSA decreases up to $20.4 \%$ 


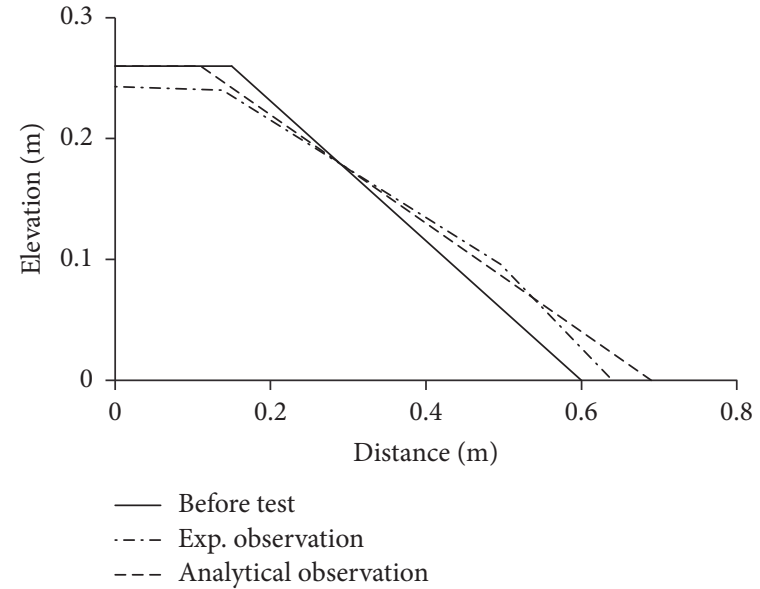

(a) Deformation of model slopes with $30^{\circ}$ inclination at $2 \mathrm{~Hz}$ frequency

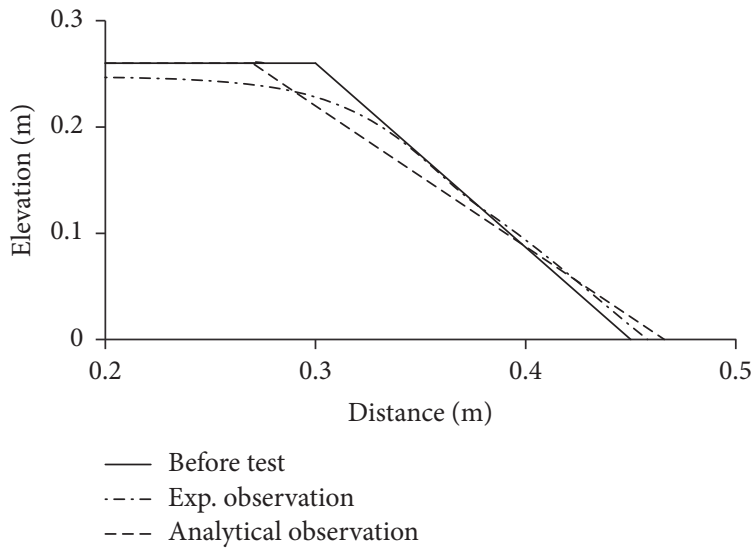

(c) Deformation of model slopes with $60^{\circ}$ inclination at $2 \mathrm{~Hz}$ frequency

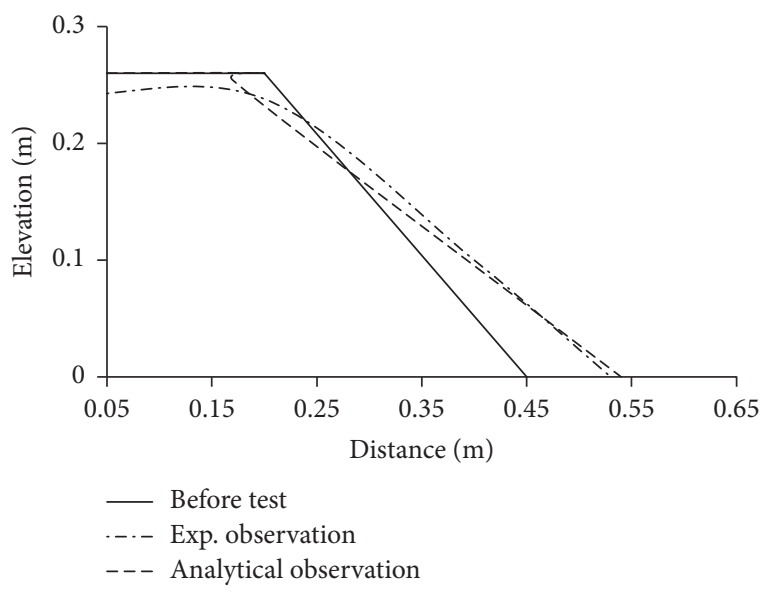

(e) Deformation of model slopes with $45^{\circ}$ inclination at $5 \mathrm{~Hz}$ frequency

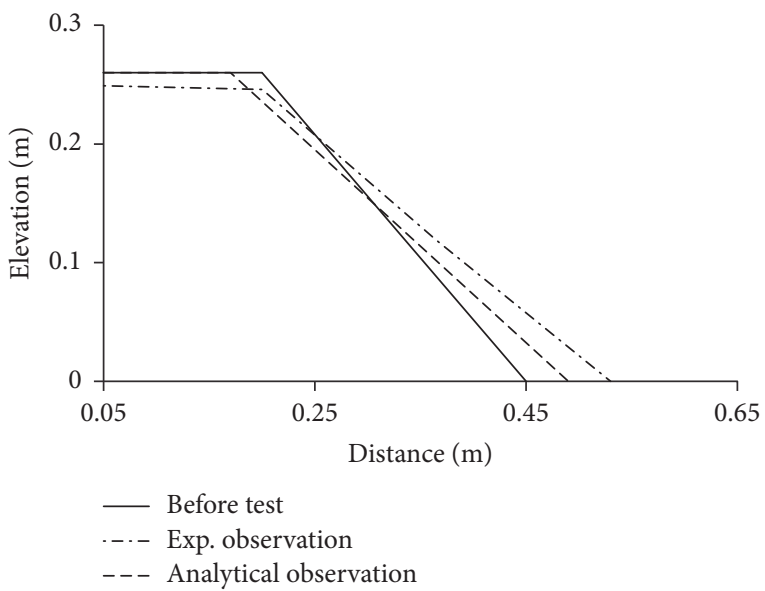

(b) Deformation of model slopes with $45^{\circ}$ inclination at $2 \mathrm{~Hz}$ frequency

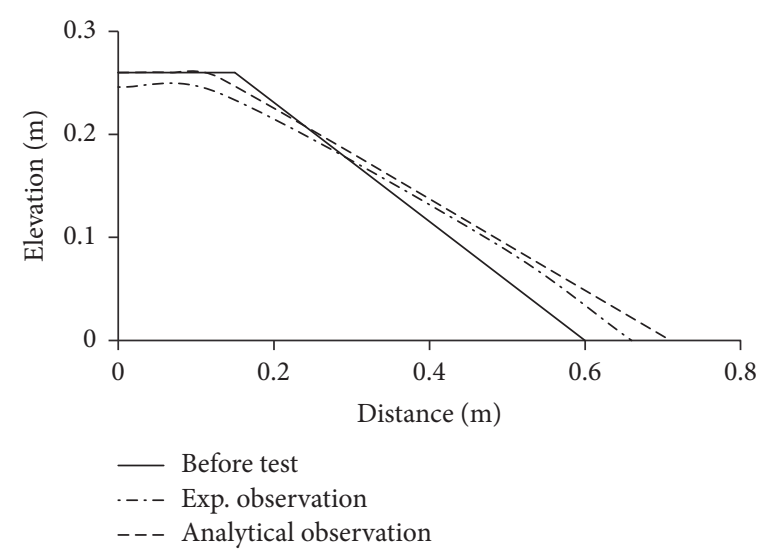

(d) Deformation of model slopes with $30^{\circ}$ inclination at $5 \mathrm{~Hz}$ frequency

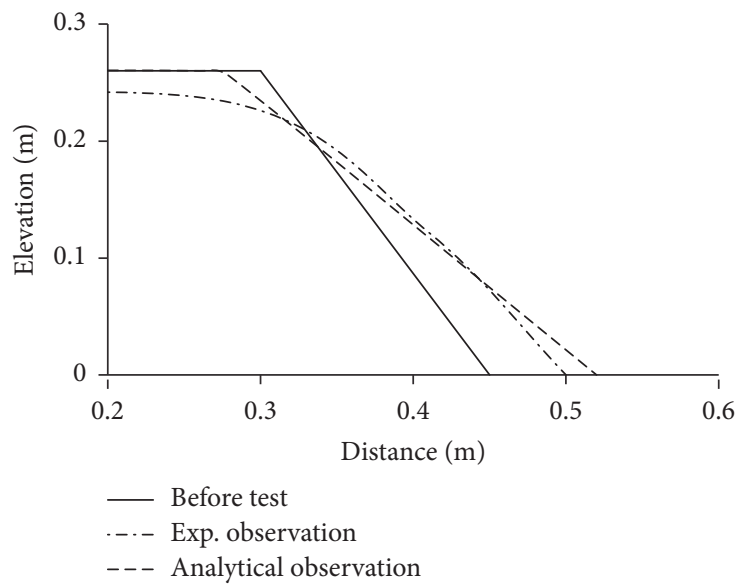

(f) Deformation of model slopes with $60^{\circ}$ inclination at $5 \mathrm{~Hz}$ frequency

FIGURE 9: Deformation of model slope measured and pattern of failure surface during shake table test and pseudodynamic analysis of slope made up of S $+30 \% \mathrm{SD}$ for frequency $2 \mathrm{~Hz}$ and $5 \mathrm{~Hz}$ at water content $6 \%$. 
TABLE 7: Sliding displacement of slope made up of S + 30\% BD from experimental result and pseudodynamic analysis.

\begin{tabular}{|c|c|c|c|c|c|}
\hline \multirow{3}{*}{ Water content (\%) } & \multirow{3}{*}{ Slope angle } & \multicolumn{4}{|c|}{ Sliding displacement (mm) } \\
\hline & & \multicolumn{2}{|c|}{$2 \mathrm{~Hz}$ frequency } & \multicolumn{2}{|c|}{$5 \mathrm{~Hz}$ frequency } \\
\hline & & Experimental result & Analytical result & Experimental result & Analytical result \\
\hline \multirow{3}{*}{0} & $30^{\circ}$ & 8 & 7.64 & 9 & 9.3 \\
\hline & $45^{\circ}$ & 8.5 & 8.68 & 10.4 & 9.89 \\
\hline & $60^{\circ}$ & 10 & 9.86 & 11 & 10.64 \\
\hline \multirow{3}{*}{3} & $30^{\circ}$ & 7.3 & 7.42 & 7.9 & 7.83 \\
\hline & $45^{\circ}$ & 7.5 & 7.49 & 8.5 & 8.2 \\
\hline & $60^{\circ}$ & 8.4 & 8.32 & 9.1 & 8.96 \\
\hline \multirow{3}{*}{6} & $30^{\circ}$ & 6.5 & 6.54 & 7 & 7.26 \\
\hline & $45^{\circ}$ & 7.1 & 7.21 & 7.8 & 7.86 \\
\hline & $60^{\circ}$ & 8 & 8.13 & 8.5 & 8.54 \\
\hline
\end{tabular}

when water content of soil changes from $3 \%$ to $6 \%$ and the similar pattern is also observed for other slope materials also. In addition results also depict stability of slope is highly dependent on slope material. At same normalized elevation and base shaking frequency RMSA decreases up to $20.8 \%$, $22.4 \%, 29.3 \%$, and $34.5 \%$ when slope material changes from "soil" to "S + 30\% WD," "S + 30\% SD," "S + 30\% BD," and "S $+30 \% \mathrm{DD}$," respectively, for model slope with $30^{\circ}$ inclination at $3 \%$ water content.

(2) Displacement of base due to seismic excitation is observed in each model slope after test and it has been clearly visible that when input motion is generated with frequency $2 \mathrm{~Hz}$ for a duration of $10 \mathrm{sec}$ on slope with $45^{\circ}$ inclination at water content $3 \%$ the " $D / B$ " ratio is highest for slope made up of soil and decreases up to $10.5 \%, 21 \%, 45 \%$, and $63 \%$ when slope material changes from "soil" to "S + 10\% WD," "S + 10\% $\mathrm{SD}$," "S + 10\% BD," and "S + 10\% DD," respectively. Similar pattern is also observed for response of slope when measured in terms of crest deformation and the " $h / H$ " ratio is reduces up to $3.8 \%, 7.7 \%, 15.4 \%$, and $23 \%$ when slope material changes from "soil" to "S + 10\% WD," "S + 10\% SD," "S + 10\% BD," and "S $+10 \% \mathrm{DD}$," respectively. Also slope model constructed with soil dust mixtures is observed to be more stable when water content of the material mixture changes from $3 \%$ to $6 \%$.

(3) Stability number critical angle of failure surface $\alpha_{c}$ of a model slope has been evaluated by pseudodynamic method. Horizontal sliding displacement of a slope in a particular soil and seismic condition is determined analytically and compared with base displacement of model slope observed in the shake table test. The pattern of failure for both analytical and experimental investigation is also presented.

\section{Conflicts of Interest}

The authors declare that there are no conflicts of interest regarding the publication of this paper.

\section{References}

[1] D. W. Taylor, "Stability of earth slopes," Four Boston Soc. Civil Engrs, vol. 24, no. 3, pp. 197-246, 1937.
[2] D. W. Taylor, Fundamentals of Soil Mechanics, Wiley, New York, USA, 1948.

[3] W. Fellenius, "Calculation of the stability of earth dams," in Transactions of the 2 nd Congress on Large Dams, vol. 4, pp. 445459, 1936.

[4] N. M. Newmark, "Effects of earthquakes on dams and embankments," Géotechnique, vol. 15, no. 2, pp. 139-160, 1965.

[5] EERI, Bhuj, India Republic Day January 26, 2001 Earthquake Reconnaissance Report, Earthquake Engineering Research Institute, New York, USA, 2001.

[6] R. W. Clough and D. Pirtz, "Earthquake resistance of rockfill dams," Journal of the Soil Mechanics and Foundations Division, vol. 82, no. 2, pp. 1-26, 1956.

[7] H. B. Seed and R. W. Clough, "Earthquake resistance of sloping core dams," Journal of the Soil Mechanics and Foundations Division, vol. 89, no. 1, pp. 209-242, 1963.

[8] R. E. Goodman and H. B. Seed, "Displacements of slopes on cohesionless materials during earthquakes," Rep. No. H21, Inst. of Trans. And Traffic Engineering, Univ. of Calif., Berkeley, Calif., 1965.

[9] I. Arango and H. B. Seed, "Seismic stability and deformation of clay slopes," Journal of the Geotechnical Engineering Division, vol. 100, no. 2, pp. 139-156, 1974.

[10] S. Iai, "Similitude for shaking table tests on soil-structure-fluid model in $1 \mathrm{~g}$ gravitational field," Soils and Foundations, vol. 29, no. 1, pp. 105-118, 1989.

[11] Y. Koga and O. Matsuo, "Shaking table tests of enbankments resting on liquefiable sandy ground," Soils and Foundations, vol. 30, no. 4, pp. 162-174, 1990.

[12] J. Wartman, R. B. Seed, and J. D. Bray, "Physical model studies of seismically induced deformations in slopes," GeoEngineering Report No. UCB/GT/01-01, UCB, 2001.

[13] J. Wartman, J. D. Bray, and R. B. Seed, "Inclined plane studies of the newmark sliding block procedure," Journal of Geotechnical and Geoenvironmental Engineering, vol. 129, no. 8, pp. 673-684, 2003.

[14] J. Wartman, R. B. Seed, and J. D. Bray, "Shaking table modeling of seismically induced deformations in slopes," Journal of Geotechnical and Geoenvironmental Engineering, vol. 131, no. 5, pp. 610-622, 2005.

[15] M. Lin and K. Wang, "Seismic slope behavior in a large-scale shaking table model test," Engineering Geology, vol. 86, no. 2-3, pp. 118-133, 2006. 
[16] S. K. Prasad, I. Towhata, G. P. Chandradhara, and P. Nanjundaswamy, "Shaking table tests in earthquake geotechnical engineering," Current Science, vol. 87, no. 10, pp. 1398-1404, 2004.

[17] H. I. Ling, D. Leshchinsky, and Y. Mohri, "Soil slopes under combined horizontal and vertical seismic accelerations," Earthquake Engineering and Structural Dynamics, vol. 26, no. 12, pp. 1231-1241, 1997.

[18] H. I. Ling, Y. Mohri, and T. Kawabata, "Seismic analysis of sliding wedge: Extended Francais-Culmann's analysis," Soil Dynamics and Earthquake Engineering, vol. 18, no. 5, pp. 387393, 1999.

[19] K. Terzaghi, "Mechanisms of Land Slides. Engineering Geology (Berkeley) Volume," Geological Society of America, 1950.

[20] R. S. Steedman and X. Zeng, "The influence of phase on the calculation of pseudo-static earth pressure on a retaining wall," Geotechnique, vol. 40, no. 1, pp. 103-112, 1990.

[21] N. Chanda, S. Ghosh, and M. Pal, "Analysis of slope considering circular rupture surface," International Journal of Geotechnical Engineering, vol. 10, no. 3, pp. 288-296, 2016.

[22] R. V. Whitman and P. C. Lambe, "Effect of boundaryconditions upon centrifuge experiments using ground motions simulations," Geotechnical Testing Journal, vol. 9, no. 2, pp. 61-71, 1986.

[23] N. Chanda, S. Ghosh, and M. Pal, "Seismic stability analysis of reinforced and unreinforced slope," in Proceedings of the 50th Indian geotechnical conference, Paper ID-381, 2015. 

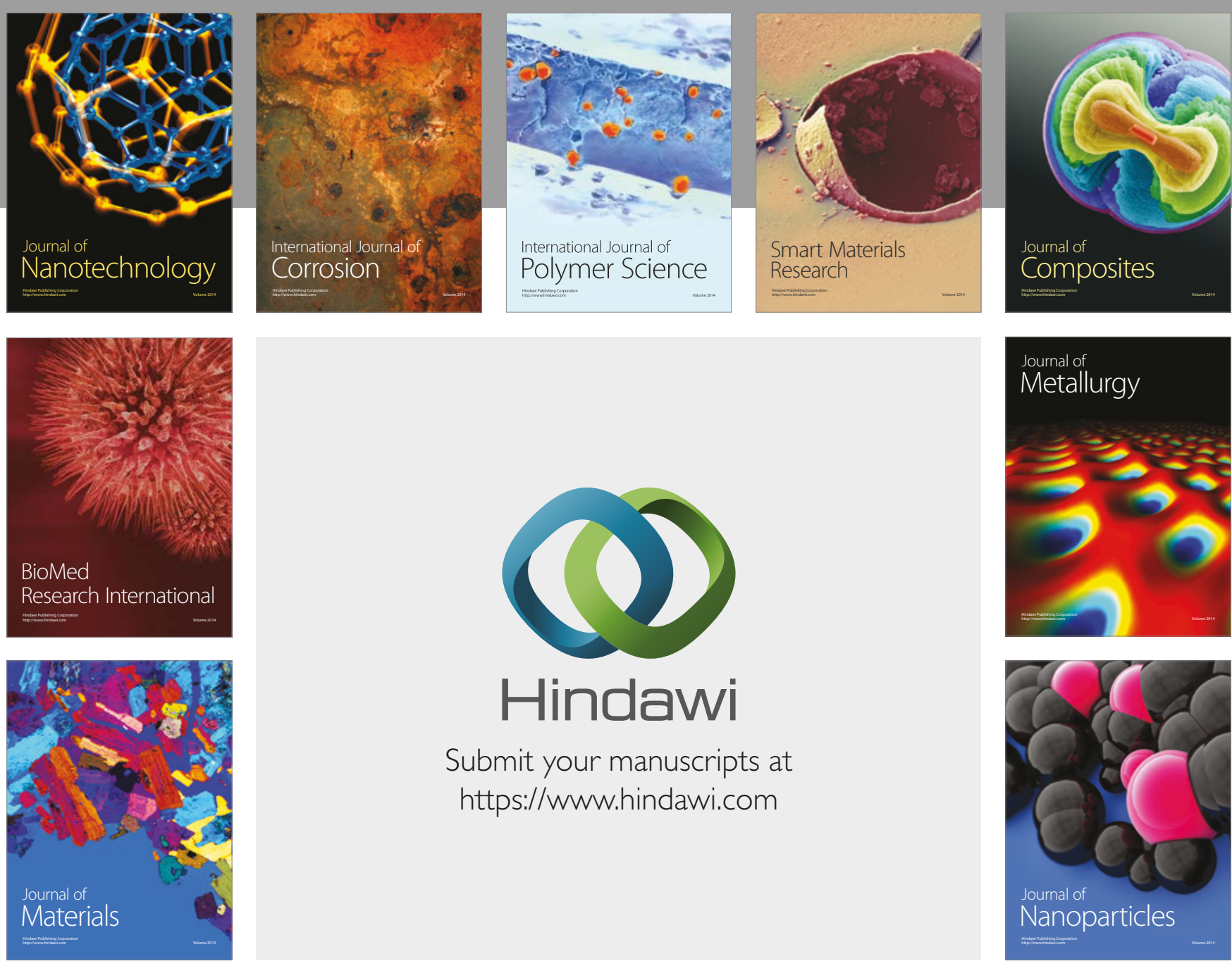

\section{Hindawi}

Submit your manuscripts at

https://www.hindawi.com
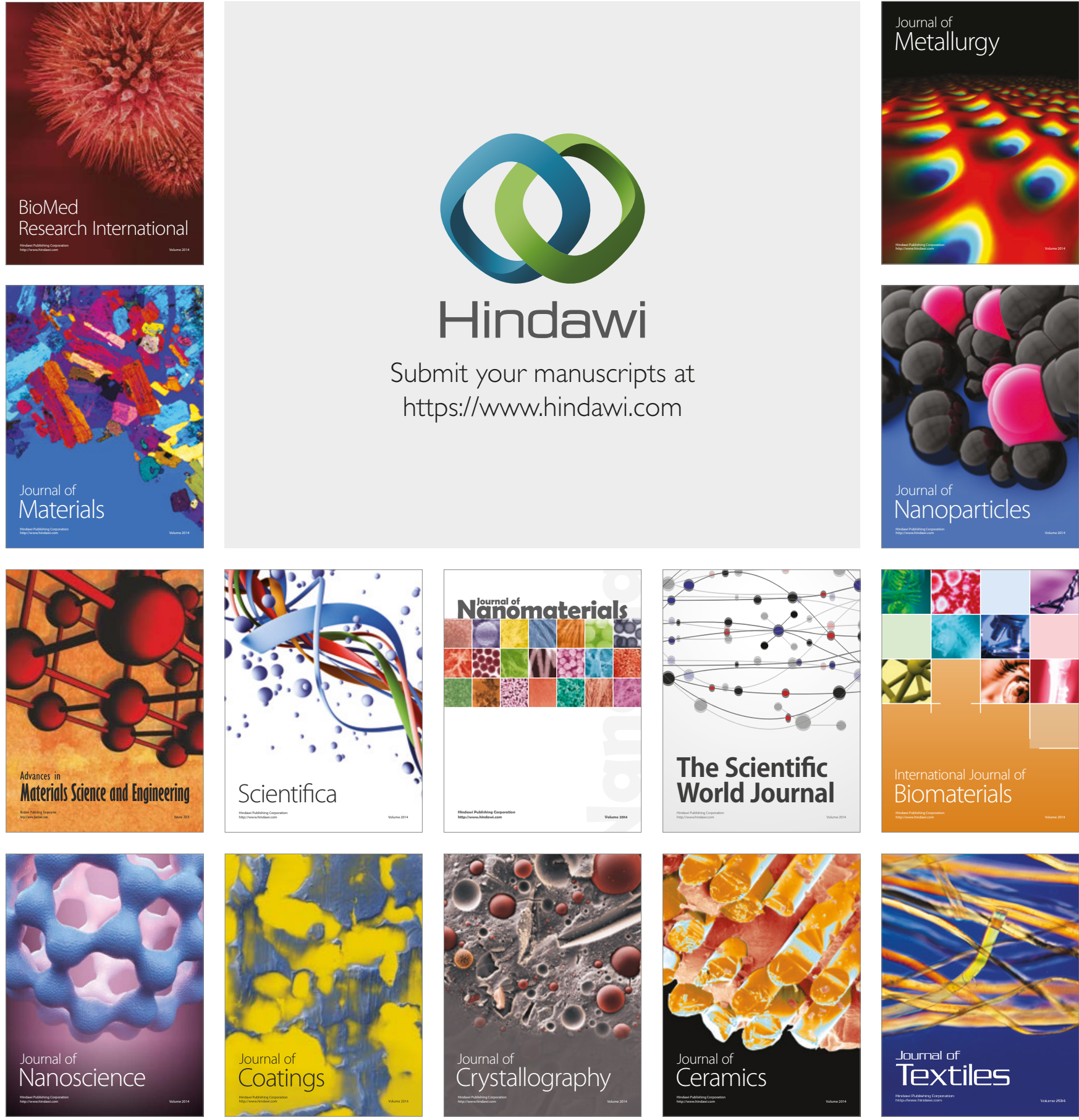

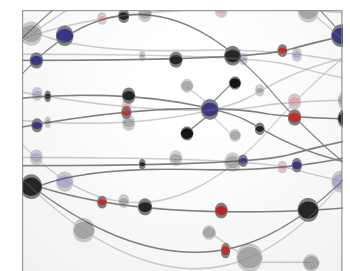

The Scientific World Journal
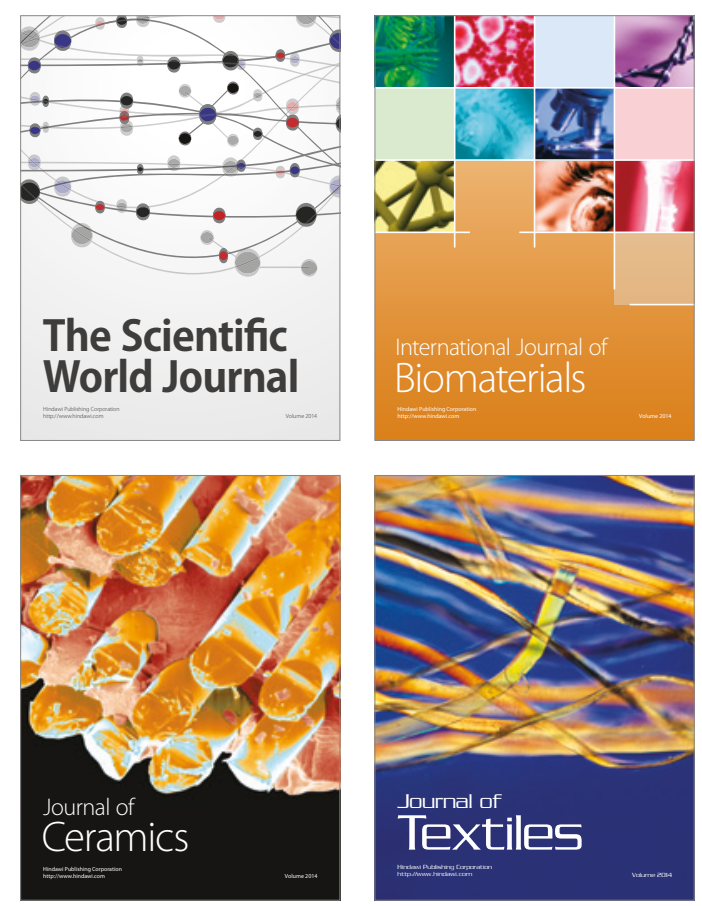